Bárbara Vignali Murakawa

EFL digital coursebooks: A genre approach

Orientadora: Prof. Dra. Barbara Jane Wilcox Hemais

Rio de Janeiro 2016.1 


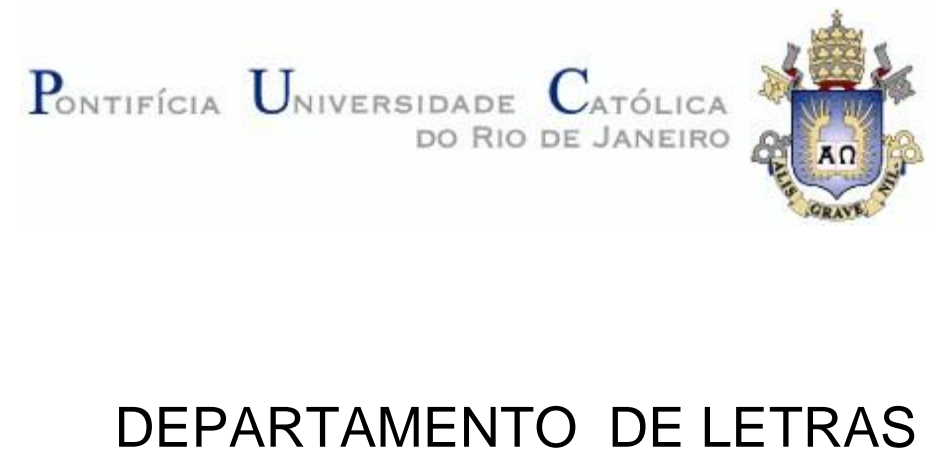

Pós-Graduação Lato Sensu em Língua Inglesa

EFL digital coursebooks: A genre approach

Bárbara Vignali Murakawa

Orientadora: Profa. Dra. Barbara Jane Wilcox Hemais 
Bárbara Vignali Murakawa

EFL digital coursebooks: A genre approach

\section{Monografia}

Monografia apresentada ao Programa de Pós-Graduação em Letras da PUC-Rio como requisito parcial para obtenção do título de Especialista em Letras.

Orientadora: Profa. Dra. Barbara Jane Wilcox Hemais

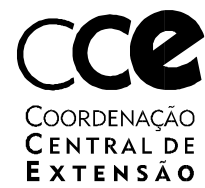

Rio de Janeiro 2016.1 
Departamento de Letras

Bárbara Vignali Murakawa

\title{
EFL digital coursebooks: A genre approach
}

\begin{abstract}
Monografia
Monografia apresentada ao Programa de Pós-Graduação em Letras da PUC-Rio como requisito parcial para obtenção do título de Especialista em Letras. Aprovada pela Comissão Examinadora abaixo assinada.
\end{abstract}

Orientadora: Profa. Dra. Barbara Jane Wilcox Hemais

Examinadora: Adriana Acioli Nóbrega

Rio de Janeiro / 2016 
Todos os direitos reservados. É proibida a reprodução total ou parcial do trabalho sem autorização do autor, do orientador e da universidade.

Bárbara Vignali Murakawa

Graduada em tradutor e interprete pelo centro educacional Anhanguera em 2011. Tem atuado como professora de língua inglesa em diversas instituições de ensino. Seus interesses são tecnologia no ensino de línguas, estudos de gênero e produção de materiais didáticos. 
When I was young, I used to expect Parisians to wear little black berets, to bicycle about with strings of onions around their necks, and to brandish long sticks of break, just like they used to do in school textbooks. 


\section{Acknowledgments}

This work is due to the support and encouragement I received from my family, friends, teachers and classmates. I would like to express my gratitude to:

○ My tutor, Barbara Hemais, for her guidance and dedication;

- My teachers in the English Studies courses for sharing their knowledge;

- My friends from Rio de Janeiro for the warm reception;

- My former classmates for all the ideas we shared;

- My friends from São Paulo for a year of listening to me talking about coursebooks;

- My parents who supported me and did everything they could so the moving to Rio was as comfortable as possible;

- Everyone else who directly or indirectly helped me accomplish this work. 


\section{ABSTRACT}

Advances in technology have reached the area of education. One sign of this is that authors and publishing houses are taking advantage of digital tools to launch electronic coursebooks. This invites a new look at concepts of genre. In this study, I analyzed seven digital EFL/ELS coursebooks through a genre perspective, considering specifically the aspects of visual features and approaches to grammar. From the results, it can be said that the similarities found in these digital books suggest the existence of a subgenre.

Key words: genre, digital genre, coursebooks, EFL/ESL coursebooks, e-books. 


\section{CONTENT}

INTRODUCTION 1

1. TEACHING MATERIALS AND EFL BOOKS 3

1.1 What are teaching materials? 3

1.2EFL books 4

1.3Multimodality in EFL books 6

1.4Approach to grammar 9

2. GENRE STUDIES 13

2.1 What is genre? 13

2.2 EFL books through a genre approach 14

2.4 Digital genre 16

3. METHODOLOGY 18

$\begin{array}{ll}3.1 \text { The sample } & 18\end{array}$

3.1 The procedures for the analysis 18

4. ANALYSES AND DISCUSSION 21

4.1 Multimodality 21

4.1.1 Images $\quad 21$

4.1.2 Spatial organization $\quad 27$

4.1.3 Videos 34

$\begin{array}{ll}4.2 \text { Approach to grammar } & 37\end{array}$

4.2.1 Comprehensibility and acceptability 37

4.2.2 Clarity and simplicity $\quad 40$

4.2.3 Focus on form vs Focus on meaning 43

4.2.4 Use of digital resources 46

5. FINAL CONSIDERATIONS 50

6. REFERENCES 54 


\section{INTRODUCTION}

Digital technology has become widely used in education and it has brought some changes to the English language classroom. Blackboards were replaced by smartboards and smart TVs and notebooks are being replaced by computers. Whether these changes are positive or not has become an important topic for discussions in the area. The market of coursebooks has also been influenced by new technologies.

Some publishing houses are already producing digital versions of their ESL/EFL coursebooks, which contain more than only text and images but also videos, audios, hyperlinks and so on. At the same time, new authors and companies are using digital tools to produce their own books and the internet to publish them at a low cost. This is a factor that might have some influence on the book market.

There are numerous studies on printed ESL/EFL coursebooks, and they have shed light on many questions concerning their effectiveness for promoting learning, use of genres, and use of grammar, for instance. On the other hand, we still lack research on digital ESL/EFL books. It is certainly a new topic and we still do not know what will be the outcome of turning books digital.

Some of the concerns are whether this change will have an impact on the book market or change the way teachers and students interact with the material. Will it bring novelty to the way we teach English? Will educational institutions replace printed books? Considering the issues surrounding digital coursebooks, I believe it to be a relevant topic that should be given attention.

In this monograph, I will be looking at the digital book for English language teaching through a genre approach. My objective is to identify elements that constitute the existence of a new genre, through the analysis of a sample of digital EFL coursebooks.

In the interest of doing so, this paper will consider the aspects of the use of multimodality and approaches to grammar. The first chapter provides a brief explanation of EFL books followed by a section on visual features, which presents the views of Bezemer and Kress (2005, 2010) and Jewitt (2006), and it ends with a section on grammar, based on the perspectives of Swan (2006) and Ur (1991).

The next chapter, which outlines theories of genre proposed by Bakhtin (2010), Marcuschi (2010) and Xavier (2010) and also addresses some other authors such as Miller (1984) and Silva (2010), shows how advances in technology might have been 
responsible for the emergence of new genres. Chapters three and four will be devoted to the analysis of EFL coursebooks published in digital format. As for the sample, I selected seven coursebooks from an online retail store. Chapter five offers final reflections on the analysis carried out and the results I obtained from it.

Distributed this way, it is hoped that this monograph meets its goal and, in the selected books, can identify features that compose a new genre. I begin this paper with a presentation on EFL materials and EFL books. 


\section{TEACHING MATERIALS AND EFL BOOKS}

This chapter will discuss several perspectives on materials and coursebooks for English language teaching. There are a number of aspects of coursebooks that can be focused on, but, for this monograph, I chose to examine the visual features found in EFL books and their approach to grammar. I believe both aspects to be pertinent for analysis. Visual elements have become predominant in traditional coursebooks and digital technology has brought the possibility of making them even more visual. Teaching grammar is usually associated with traditional approaches to language learning and the digitalization of coursebooks might be a chance to offer new ways of teaching.

In this first part of the chapter, I will present some ideas of what teaching materials and EFL books are. Then, I will summarize some of the main concepts of the use of images and other semiosis and, in addition, some ways to approach grammar. We still lack research on digital textbooks; thus most of the theories used in this chapter refer to printed books, although I would like to clarify this is not a comparative study. Nevertheless, I believe these ideas will be useful and bring some insights to my objective, which is to examine digital EFL books and identify some of their main characteristics.

\subsection{What are teaching materials?}

According to Tomlinson (2003, p.2) the term "materials" in foreign language teaching means "anything which can be used to facilitate the learning of a language". Although the book might be considered the main one, dictionaries, posters, audios, and so on are also considered teaching materials.

New advances in technologies have brought new possibilities for language teaching, especially with the use of the Internet. Nowadays, blogs and other social networks are widely used in the classroom. "Orkut, YouTube, Twitter and Facebook 
were not created as educational tools, but they can be and are used for it" 1 (VILAÇA. 2012, p.1205). Even though these medias were created for social interaction, they are also serving teaching purposes, that is, they can be considered as teaching materials.

Other digital devices such as computers, smartphones and tablets are becoming more popular in education. According to Vilaça (2012, p.1202) "the tablet, owing to the advantages of the high level of portability, mobility and resources, has sometimes been called the new notebooks and books." 2 It is important to say that it is still early to tell how long it will be necessary for tablets to be adopted by most educational institutions or even whether it happen someday. It seems, though, that digital books are becoming more popular at schools. According to a survey by School library journal, 66\% of schools across the United States already offered ebooks to their students in 2014 (Survey of E-books usage in schools, 2015). In Brazil, $40 \%$ of private schools are currently using digital books (FENEP, 2015).

\subsection{EFL Books}

In this research, I will analyze digital course books for English. Not much has yet been studied about the topic, so I will base my analysis on what some authors have said about what printed course books are and how they are produced.

It was mentioned above that anything used in a lesson to facilitate learning can be considered as teaching material. I would like to focus on EFL books because they are very much used and have an important role in class. Chris Mares, a researcher at the University of Maine, believes that "coursebooks are designed to give cohesion to the language teaching and learning process by providing direction, support and specific language-based activities aimed at offering classroom practice for students" (2003, p.130). In other words, in most classrooms, the book is still responsible for

\footnotetext{
1 Orkut, YouTube, Twitter e Facebook também não foram criados como ferramentas educacionais, mas podem e são empregados para isso. Vilaça, M. L. C. Tecnologias e livros didáticos de línguas: novas possibilidades, novos desafios. Cadernos do CNLF, Vol. XVI, № 04, t. 1 - Anais do XVI CNLF, pág. 5160, 2012.

${ }^{2} \mathrm{O}$ tablet, devido às vantagens do elevado nível de portabilidade, mobilidade e recursos, tem sido por vezes apontado como os novos cadernos e livros. Vilaça, M. L. C. Tecnologias e livros didáticos de línguas: novas possibilidades, novos desafios. Cadernos do CNLF, Vol. XVI, № 04, t. 1 - Anais do XVI CNLF, pág. 51-60, 2012.
} 
shaping the lesson by providing the topics and the procedures both teacher and students should follow.

Mares (2003) examined some English coursebooks considered to be mainstream, and what he noticed is that traditional course books of English are linear, beginning with simple topics and moving to more complex ones. Most grammar topics are contextualized and they are said to aim at communication, even though most of them seem to have a considerable repetition of chunks. They are production based. They are designed to make students use the language as soon as possible, so as to justify their communicative purpose. Further on in the analysis, we will be seeing whether digital EFL books present characteristics that are associated with a coursebook for English teaching.

Now we will outline some reasons for these books apparently following similar patterns. Why do most authors write coursebooks? Most probably the reason is that they are unhappy with the books found in the market and wish to produce more effective material. Nevertheless, according to Mares, the market of commercial materials is conservative, and ambitious pilots are usually turned down by publishers. "The tendency, however, is for publishers to look for materials that fall under a general umbrella of acceptability yet have a twist or pizzazz that make them marketable." (MARES, p. 132). Writing a course book is only a small part of the process; there are contracts with publishing houses that are interested in the market rather than pedagogy.

Littlejohn (2014) agrees that, due to neo-liberalist ideologies, the market has a great influence on education. The author says that: "every aspect of human interaction becomes subjected to the market. For this to happen, services, such as education, need to be 'commodified"' (p.2). This standardization is turning education into a product that can be sold and bought.

Soares (2007) conducted a study with three Brazilian authors of EFL material and came to the conclusion that publishing a book is a collective work rather than individual, and in which different people are involved. For the author, a coursebook "is the final product of the combination of ideas of individuals and different professionals" 3

\footnotetext{
3 O LD para o ensino de LI se constitui o produto final da conjunção das idéias de indivíduos e profissionais diferentes. Soares, M. O papel do autor de livro didático para o ensino de língua inglesa
} 
(p.104). While the author is responsible for the methodology and developing the syllabus, there is also the work by the reviewers, editors, illustrators and even the teachers who pilot and evaluate the book.

In this monograph, I will not discuss the process of writing or publishing a coursebook. However, I decided to include some of the views above as they show how the book market and the different contributions to the publication are also responsible for characterizing them. Regarding digital books, we might question whether the process of publishing them has any influence on some of the aspects of the books. A full treatment of this question is beyond the scope of this work. It will, though, be addressed partially in the final comments.

In this first part of the chapter, I discussed the notion that the use of digital technologies in the classroom has increased significantly in recent years. Yet, the coursebook remains one of the main teaching materials. Some research on EFL books shows that they seem to follow a pattern in order to please the book market, which tends to be conservative. Now, I will introduce two important aspects of EFL coursebooks: multimodality and approaches to grammar.

\subsection{Multimodality in EFL books}

It is unquestionable that coursebooks have become more visual throughout the years. A study of English textbooks for native learners by Bezemer and Kress (2010) shows that:

The number of images in textbooks for English have increased significantly, from an average of virtually no images at all $(0.03$ images per page) in the 1930s, to 2 in every 4 pages ( 0.54 images per page) in the 1980 s, to 3 in every 4 pages $(0.74$ images per page) in the 2000s (p. 251).

In some cases, these images are connected to a written text and if they were omitted the writing would still make sense. This does not mean the images bring no meaning to the text. On the contrary, they are there to exemplify the written text

como uma língua estrangeira: um estudo de identidade autoral. Mestrado-[s.l.] PUC- Rio, 2007.PUCRio, 2007. 
(Martinec and Salway, 2005 in Bezemer and Kress). They show details that cannot be seen in the writing. As well as that, adding images is a manner of "reconfiguring social relations between authors and readers" (Bezemer and Kress, 2005). For instance, a poem in a textbook which might be socially considered of a high status (more sophisticated), is softened when accompanied by an illustration, which might be considered of a lower status (more popular). In addition to that, students might start to create meaning before reading the poem by looking at the image.

Each resource (writing, images, sound effects, colors, gestures, and so on) that contributes to meaning is called a "mode". Kress (2010, p. 79 ) defines mode as a "socially shaped and culturally given semiotic resource for making meaning". Modes are shaped through their social use and they are subject to change throughout time or from place to place. The semiotic of a particular mode has a shared meaning within a community. Different modes have different potentials and limitations; thus the choices of different modes will have different effects on communication. The way in which modes are combined in order to make meaning is called multimodality.

Advances in technology have made multimodality more prevalent, and as a result more research on the subject has been developed in recent years. It may not be surprising that the area of education is enthusiastic about how technology has brought multimodality to learning. A reason for this might be that the range of modes contributes to learning (Jewitt, 2006). Students can learn from all modes and not only from written text. Here I will explain how multimodal design can shape learning.

Jewitt (2006) sees learning as a process of internalization. Meaning is realized in relation to a person's present and past experience. "Students take in and re-make semiotic resources" (p. 105). As was mentioned before, different features are not included in a text simply for decoration, but to add meaning to it. Even writing is becoming more visual. Students are able to recognize the role of the writing by its font, color, or size. For instance, a text might be written in black, but new vocabulary within this text might be in blue. In some contexts, writing has become irrelevant. Some instructions are delivered more effectively if shown as a visual sign instead of being written. Images and videos can also include some details and pieces of information that other modes such as audio or writing cannot. Multimodality changes the representation students make of the text. 
Modes can mediate the relationship of students with what is to be learnt. The choices of modes will tell what is more or less important. As well as that, multimodality can provide students with more autonomy. It enables them to select how to engage with the text. For instance, some students do not "trust" images and might choose to ignore them, while others use the same pictures to contextualize the text. This is what Jewitt (2006) calls modal "preferences". Multimodality can also put students in different positions, as some of them might prefer to be an observer while others will prefer a more active role. Digital books that have games and other interactive activities will allow that.

As regards the visual structure of the material, it can also impact learning. Students might make epistemic judgments of the material by its appearance. For instance, a grey layout might transmit seriousness. In addition, the visual structure of the material offers the potential for comparison of different texts, and it allows multimodal metaphors of the real world (Jewitt, 2006). The organization of the space within a page is also to be taken into account as it can offer particular views (Kress and Van Leeuwen, 1996 in Rose, 2007). Kress and Van Leeuween say, for example, that frontal angles engage the viewer with the image more than oblique angles. In the analysis of multimodality, I will check how the spatial organization of the pages influences the way students might interact with the material.

The use of different features can contribute to learning and it changes the way students interact with the material. In the analysis of digital EFL coursebooks, I will put these concepts into practice to examine the exploration of multimodality in the EFL digital books I selected and present some predictions about how much it might affect what is learned in the English language classroom. In this study I cannot foresee what students will learn but what is available for them to learn. In the next section, I will present some ways of introducing grammatical topics, which is also the subject of analysis in this research paper. 


\subsection{Approach to grammar}

In recent years, the teaching of grammar has been downgraded and many teachers have questioned whether they should or should not teach grammatical structures. On the other hand, for many learners as well as teachers, learning a foreign language is still strongly related to knowing its grammar. In average English classrooms, grammar presentations are a large part of lessons, and grammatical structures are present in most EFL books. Each book has its own way to approach grammar and these approaches might change from time to time and according to the author's or institution's beliefs.

Despite the fact that most of the books that I will analyze have been described as communicative, I do not intend to focus on methodologies. My intention is to investigate whether digital books have new means of introducing grammar or still use more traditional approaches, similar to printed books. The concept of new and traditional will be discussed in this chapter.

Swan (2006) justifies this questioning of whether we should teach grammar or not, saying there is a disappointment with the results of the teaching program that is heavily based on grammar. Students memorize lists of verbs but struggle to perform simple tasks such as ordering a cup of coffee.

Swan believes that the rise of new approaches for teaching has also contributed to the decline of grammar teaching. More communicative approaches focus on meaning and contextualized language, instead of on structures. The author summarizes two different views; the first one is associated with Stephen Krashen's theory that explicit learning of language structures cannot lead to "language acquisition" since it is not produced spontaneously. The second one, post-Krashen, believes that the study of grammar is only effective if associated with communicative use. Finally, Swan talks about the lexical approach, in which students learn language as "chunks".

Swan, however, believes in the teaching of grammar and states that "where time is limited and learners have little out-of-class exposure, this [grammar awareness] can only be brought about with the help of pedagogical intervention" (2006, n.p.). In addition 
to that, Swan does not believe that the study of lexis is sufficient. Some structures of the language are complex and should be studied as such. Additionally, there is no evidence that the study of lexical chunks is more effective than explicit grammar exposure.

There are, though, some criteria proposed by Swan for the teaching of grammatical structures. He believes teachers should select what will be more effective and useful for students. First, he refers to comprehensibility and acceptability. The first term means being able to communicate effectively even though the language used is not completely accurate. This concept might be said to oppose acceptability, which is related to the pressure many suffer in order to achieve a high level of accuracy and not be seen to be uneducated or unintelligent.

The scope of a grammar rule, the frequency in which it appears and its relevance should also be taken into account. It is the teacher's decision to give priority to one or another grammar topic, and this will depend on the students' needs and previous knowledge. According to Swan "The grammar that we teach should relate to learners' problems with English" (2006, n.p.).

With regard to language presentation, Swan believes explanations do not need to give the whole truth, but should be short, clear and preferably in the students' mother tongue. This last piece of information is particularly surprising, as most EFL books introduce language in English. Swans says that the prohibition of the mother tongue is an "old dogma" and "has not been taken seriously by linguistics for decades" (2005, n.p.). Finally, Swan talks about exercises. He says that communicative approaches have brought a considerable amount of real life and meaningful activities to the language classroom and these are believed to be superior to more mechanical exercises such as gap-filling. However, although these exercises might not be very communicative, they should not be ignored. They help students to work on form and accuracy, important aspects in grammar learning.

Penny Ur (1991, p. 87) defines grammar as a "set of rules that defines how words (or part of words) are combined or changed to form acceptable units of meaning within a language". The author is concerned about two things: form and meaning. She is considering the order of words in a sentence, the addition of suffixes in a word to 
make plural or past tense, and so on, and the significance of these combinations of words in English.

Ur (1991) says that textbooks tend to focus mainly on form, or structure, while meaning is usually ignored. She argues that knowing how to construct sentences is not enough if you do not know what they mean and how to use them. She also believes that teaching meaning is the most difficult part of presenting grammar, as most English speakers do not stop to think about it but simply speak the language intuitively.

Most authors (Newmark, 1979; Widdowson, 1979; Hawkins, 1984 in Ur, 1991) agree that learning grammatical structures is insufficient for being able to communicate properly in English. Hawkins even criticizes the use of traditional prescriptive rules. Ur believes grammar rules are helpful, as long as they are used as a means to improve mastery of the language.

Regarding language presentation, Ur says that there should be a balance between simplicity and accuracy. The presentation has to be clear and simple so learners can understand, but, if the explanation is overly simple, it might not be accurate. On the other hand, a complete explanation of the structure might be confusing. According to the author "as a rule, a simple generalization, even if not entirely accurate, is more helpful to learners than a detailed grammar-book definition" (p. 83).

In addition to that, Ur thinks that a good grammar presentation should include both oral and written form and meaning. It should be contextualized and if possible should include visual materials. Some other aspects will depend on the teacher and/or students. Using terminologies such as "adverbs," "pronouns," and so on, as well as giving explicit explanations of grammar rules might work well for analytical-minded students and older students that are more used to traditional approaches.

In summary, whether to teach grammar or not is a controversial topic. In order to make a decision, we should take into consideration what the students need and what grammar topics should be prioritized. More traditional approaches tend to focus on grammar structure and a set of rules to be memorized. However, teaching meaning and use is just as important. Grammar explanations should be clear, simple, contextualized and could include visual material. This is what should be expected from new approaches to grammar. 


\section{GENRE STUDIES}

This chapter will be dedicated to genre studies. First, I will present the genre theory proposed by Mikhail Bakhtin. Then, to complement Bakhtin's thought I will present some other theoretical discussions about genre and the EFL coursebook as a genre. Finally, I will talk about some new genres that have emerged in the context of digital technologies.

\subsection{What is Genre?}

The concept of speech genre proposed by Mikhail Bakhtin is directly linked to the various fields of human activity. The author says that man is a socio-historical being; therefore, the study of language can only occur within interaction (Bakhtin, [1979] 2010). Unlike the structuralist method of Saussure, whose aim was to study the language as a system (SAUSSURE 1995, p. 14), Bakhtin was concerned to study language through oral and written utterances.

These utterances are the product of social interaction and vary in content, style and compositional construction; in addition, they adapt to a particular field of communication, e.g. the scientific language of biologists. According to Bakhtin ([1979] 2010, p. 261), "Each separate utterance is individual, of course, but each sphere in which language is used develops its own relatively stable types of these utterances". The term "relatively stable" is used because, in a society, genres carry features that have some degree of regularity, but, in addition, genres can change to meet the needs of that society.

This notion of a sphere developing its particular "relatively stable" utterances, which we recognize as genres, is pertinent to the study of EFL/ESL coursebooks. In fact, EFL/ESL books go through reformulations from time to time. Take, for instance, the use of the word "New" in the title of some books that are reissued (Silva, 2015). Throughout the years, a course book might present more or fewer pictures, for example, or different kinds of exercises, or authentic or made-up texts. These modifications are due to changes in pedagogical practices, the coming of new ways of teaching as well as advances in technology. Souza (1999) believes these changes to be motivated by the market. A book might be edited simply to receive the appearance 
of a new and recently released publication. Further on, I will investigate whether digital coursebooks are also revised or not. This will be an important step in this paper, which aims to study the digital course book of English as a genre.

Bakhtin decided to divide the genres into primary (simple) and secondary (complex). It is important to remember that this difference is not functional. Secondary genres are mediated by writing, shaped through a more complex and developed culture, and realized in written texts such as novels and scientific papers, while primary genres are related to daily, informal and immediate communication. During the process of their formation, the secondary genres incorporate some of the primary ones. As an example, Bakhtin cites a letter or a dialogue inserted into a novel. It is no longer everyday verbal activity, but an artistic verbal activity. Both the novel and the everyday conversation are formed by verbal statements, therefore, they have a common nature. Only the level of complexity as well as the purpose of one and the other distinguish them.

In the context of EFL books ${ }^{4}$, it is possible to find various examples of this: a dialogue in which students have to practice in pairs; an interview for students to read; an article or a fragment of a poem. These are all genres incorporated into the coursebook, which is considered to be a secondary genre itself. The interview, the article and poem no longer serve for the same everyday communicative activity, but now are part of a pedagogical activity.

In this part of the chapter I presented the theory of genre proposed by Mikhail Bakhtin. There are other views of genre that are relevant for a discussion of EFL books. Some of these views will be presented next.

\subsection{EFL books through a genre approach}

We acknowledged that genres are products of social interaction that happens within the linguistic community. In the same line of thought, Bhatia (2004) says that:

Genre essentially refers to language use in a conventionalized communicative setting in order to give expression to a specific set of communicative goals of a

\footnotetext{
${ }^{4}$ Book or books are used to mean the same as coursebook and coursebooks throughout the text.
} 
disciplinary or social institution, which give rise to stable structural forms by imposing constraints on the use of lexico-grammatical as well as discoursal resources. (p. 23)

That is, genre is how we use language to perform tasks, or how we use language to reach our communicative goals. In order to be successful in communication we make specific linguistic choices. These choices not only are determined by the genre but also characterize it.

Genres should be defined by the action they are used to accomplish, in other words, by their function instead of their form of discourse. On the other hand, we should not disqualify the compositional construction. As was already mentioned, compositional construction as well as content and style are the three characteristics of genres in Bakhtin's theory, and this perspective has been followed by other genre scholars. Dirk (2009) says that: "by studying the genres that we find familiar, we can start to see how specific choices that writers make result in specific actions on the part of readers" (p. 254).

According to Silva (2015), coursebooks of English fit the concepts of genre mentioned above. They are linguistic resources which are involved in a social practice. They are part of teachers and students' routine and most of the times they are the most important instrument in the English classroom. In addition, their compositional structures are relatively stable, considering they follow several requirements of the publishing industry such as mentioning author, their target public, and copyrights. Furthermore, the language used in this kind of English teaching material tends to be recurrent, for instance, imperatives, images, icons, and other genres are consistently included in the course books.

In English (EFL) teaching, genres might change according to their pedagogical purpose (Hemais, 2015). These changes can occur in grammatical and lexical aspects as well as in the relationship between the participants. At first, in the original situation of communication, the relation was between author and reader, or between biologists, or candidate and interviewer, for instance. But then it became a relationship between teacher, students and material. I have said that course books are composed of different genres, some of them originally primary, which are related to real, everyday communication. When inserted in the pedagogical context, these genres gain a new purpose. As an example, Hemais mentions a recipe. Originally, its objective is to demonstrate how to prepare a certain dish, but in the educational context its objective 
is to teach language. It is expected, though, that students learn more than grammar and vocabulary and begin to recognize these as social actions. That is important if learners are to become participants in the community of genre users.

According to Halliday and Hasan (1983 in Silva 2015, p. 37), genres are products of a context of culture, which is a set of human activities. From this perspective, Halliday (1991, in Silva 2015) suggests the existence of an educational culture, that is, an organized social activity that aims to educate. Considering that EFL books have an important role in the classroom, we could say that they belong to an educational culture. Still following the concept proposed by Halliday and Hasan, in the present moment, the use of digital equipment is part of our daily lives. We may say that digital medias have become part of our context of culture. In the next section, I will explain how the use of technology helped the rise of new genres.

\subsection{Digital genres}

Due to the emergence of new technologies, there has also been an emergence of new genres. It is not the technology itself that is responsible for this change, but the intensity in which it is used and its interference in communicative activities (Marcuschi, 2010). Thus, the major media such as newspapers, magazines, radio, television, and internet are providing and incorporating new ways of communicating such as conference calls, live reports, emails, online networking, virtual classes, and so on.

There is no absolute innovation that is unlinked to an existing genre. According to Bakhtin([1979] 2010), a genre goes through a transmutation, forming a new one. We can take as an example a phone call, which is similar to a face-to-face conversation, though it happens through an electronic device. Or the e-mail, which generates a virtual message, but grew out of letters and notes. Consequently, we might also say that digital books transmuted from printed books. This is an important assumption for the analysis that will come later.

These emerging genres that have arisen in the context of different media create their own communicative means and allow us to observe the integration of various types of semiosis such as text, sound and image. Although a genre is not defined by 
its form or structure but by social, communicative and functional aspects, there are cases where the medium or environment in which the text appears determines the genre (Marcuschi, 2010).

Therefore, it can be argued that EFL digital books are not the same as printed EFL books for two reasons. First, they are part of a different cultural and social context, a culture that is highly connected to digital technologies. Second, they happen in a different environment. Digital publications rely on either a tablet, a cellphone or a computer. They might have originated from printed coursebooks, but they are no longer the same books.

To summarize, genres are products of social interaction that develops within different fields of communication. Genres are relatively stable, though they might undergo some changes from time to time. The EFL book is a genre that goes through transformations according to the changes in pedagogical practices or market demands. Developments in digital technology have changed the way we communicate and resulted in the emergence of new genres such as calls and e-mails. Books have also become digital, suggesting the existence of a new digital genre. By looking at some of these aspects, I expect to identify a genre in EFL digital coursebooks. 


\section{METHODOLOGY}

This chapter will provide details concerning how the analysis was carried out. It provides a general overview of the digital EFL books and the criteria used for their selection. My aim in writing this monograph is to identify characteristics that constitute the existence of a new genre, through the analysis of digital EFL coursebooks. Understanding the role of visuality in the teaching-learning process and assessing whether digital technology has contributed to new ways of teaching grammar are also part of my objective.

\subsection{The sample}

The books to be included in the sample for analysis had to meet several criteria. First of all, they are digital books for general English rather than for specific purposes. Second, their level of English varies from A1 to B2 according to the Common European Framework of Reference for Language (CEFR). And last, all publications are classified as "made for ibooks", which means they have been designed and programmed for Apple Inc. The reason for the last criterion is that the electronic device I have available is an IPad.

In order to find those books, I entered the iBooks store and searched for the following terms: English textbook, learning English, EFL books and ESL books. As a result, I encountered seven books that fit the criteria mentioned above. I expected to find more mainstream books that are published by big publishing houses and that have previous publications in print. However, most of the books found in my research seem to be exclusively digital and developed by smaller companies and independent authors. In each book, I analyzed one chapter that was chosen at random, mostly according to what was available for download as a free sample. 


\subsection{The procedures for the analysis}

I created a chart (Figure 1) to gather relevant information about each digital coursebook. It is divided into title of the book, publisher, author, year of publication, medias used, traditional or non-traditional approach to grammar, and the book description.

The first aspect of the analysis is the study of visual features. To do so, I used an approach called compositional interpretation. It was developed by Gillian Rose (2006) and it pays most attention to the compositionality of images themselves. The IPad is a touchscreen equipment that can reproduce videos and sounds and create movement when you tap the screen. I took advantage of this tool to analyze the coursebooks in terms of multimodality. The concept of multimodality is too extensive to fit in a monograph, so I limited my analysis to images, spatial organization and videos.

The second aspect to be investigated is grammar teaching. In the unit of each book, I identified characteristics of the approach following Swan's (2006) and Ur's (1991) views of the teaching of grammar. I specifically considered the following items:

- Comprehensibility

- Acceptability

- Clarity

- Simplicity

- Focus on form vs. focus on meaning

- Use of digital resources

The last item refers to how the Ipad resources, such as sounds, videos, minimization and expansion of pages, can contribute to the teaching of grammar. I believe that searching for similarities and differences among the books will show some evidence of whether these publications can be considered as a sign of a new digital genre or not. The results of this analysis will be shown in the next chapter. 
FIGURE 1 - EFL DIGITAL BOOKS

\begin{tabular}{|c|c|c|c|c|c|}
\hline $\begin{array}{l}\text { NEW HEADWAY PRE- } \\
\text { INTERMEDIATE }\end{array}$ & OXFORD UNVERSITY PRESS & January, 2014 & JOHN SOARS \& LIZ SOARS & $\begin{array}{l}\text { Pictures, audio,click on } \\
\text { exercises, hyperlinks, } \\
\text { movement, self-checking, }\end{array}$ & $\begin{array}{l}\text { The world's best-selling English course - a perfectly balanced sylllabus } \\
\text { with a strong grammar focus, and full support. The strong grammar focus, } \\
\text { clear voca bulary syllabus and integrated skills work give you lessons that } \\
\text { really work in class. The Headway eaook includes the first six units of the } \\
\text { new, 4th edition of the pre-intermediate level of world's most trusted } \\
\text { English course, with interactive exercises and video. Tried and tested all } \\
\text { over the world, Headway is the course that teachers and learners rely on. }\end{array}$ \\
\hline $\begin{array}{c}\text { iLook, iThink, ispeak English } \\
\text { Practice - Technology }\end{array}$ & Zapa eBooks & January, 2013 & $\begin{array}{l}\text { Robert Hextall, Darren } \\
\text { Kurien, Pablo Ruiz \& John } \\
\text { Hird }\end{array}$ & $\begin{array}{l}\text { pictures, audios, hyperlinks, } \\
\text { click on exercises, videos. }\end{array}$ & $\begin{array}{c}\text { Practice and improve your English with this B1-C1 level book (for } \\
\text { both learners and trainers). } 5 \text { units with articles on Technology and } \\
\text { the future of our world. All units contain listening, reading and } \\
\text { pronunciation practice with audios, glossaries and extra activitites. } \\
\text { Everything is included in the download! Start improving your } \\
\text { English now! }\end{array}$ \\
\hline $\begin{array}{l}\text { Learn English - Level 4: } \\
\text { intermediate English } \\
\text { (Enhanced Version) }\end{array}$ & $\begin{array}{l}\text { Innovative Language } \\
\text { learning }\end{array}$ & January, 2012 & $\begin{array}{l}\text { Innovative Language } \\
\text { Learning, LLC }\end{array}$ & Audio,s hyperlinks & $\begin{array}{l}\text { Interactive. Effective. And Fun! Start speaking English in minutes, and learn } \\
\text { key vocabulary, phrases, and gramar in just minutes more with } \\
\text { Intermediate - English, a completely new way to learn English with ease! } \\
\text { Intermediate - English will arm you with English and cultural insight to } \\
\text { utterly shock and amaze your English friends and family, teachers, and } \\
\text { coll leagues. Whay you get in Intermediate English }\end{array}$ \\
\hline Upto Date 5 & Grand Duc em ligne & December, 2013 & $\begin{array}{l}\text { Benoit Jaret \& Stravos } \\
\text { Antoniadis }\end{array}$ & $\begin{array}{l}\text { Images, click on exercises, } \\
\text { self-checking }\end{array}$ & $\begin{array}{l}\text { The new series UptoDate for teaching English as a second language: } \\
\text { - Updates knowledge to keep pace with the progression of learning } \\
\text { - Dusts off grammar essentials } \\
\text { - Revamps its presentation to motivate students }\end{array}$ \\
\hline Study it 3 & $\begin{array}{l}\text { Connect School of } \\
\text { Languages Inc. }\end{array}$ & October, 2013 & $\begin{array}{l}\text { James Rice \& Jamie } \\
\text { Matechuk }\end{array}$ & $\begin{array}{l}\text { Images, videos, click on } \\
\text { exercises, self-checking }\end{array}$ & 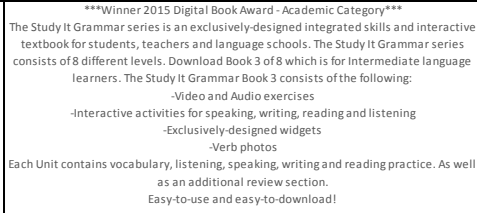 \\
\hline $\begin{array}{c}\text { Breaking the English Barrier } \\
\text { Level } 1\end{array}$ & Breaking the Barrier & May, 2014 & John Conner \& Miguel Romá & $\begin{array}{l}\text { Images, audios, click on } \\
\text { exercises, self-checking }\end{array}$ & 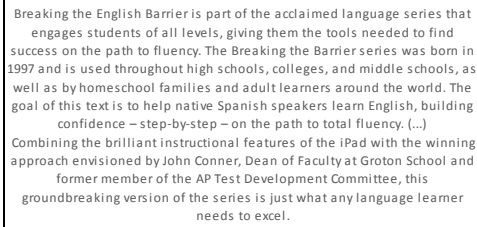 \\
\hline $\begin{array}{l}\text { In Class English Speaking } \\
\text { Course Book } 1\end{array}$ & Ipad Materials Publishing & February, 2015 & Kodani Hiroshi & $\begin{array}{l}\text { Images, videos, click on } \\
\text { exercises, self-checking }\end{array}$ & $\begin{array}{l}\text { ESL textbook. This Textbook contains American English Speaking and } \\
\text { talking Lessons. It has } 18 \text { Lessons and it is edited for non-native Engli ish } \\
\text { learners. (English as a Second Language) Especially, readers can learn } \\
\text { every day speaking phrases. }\end{array}$ \\
\hline
\end{tabular}




\section{ANALYSIS AND DISCUSSION}

This chapter presents the analysis and discussion of the selected EFL digital books in terms of multimodality and the approach to grammar.

\subsection{Multimodality}

The first concept to be analyzed in this monograph is the use of multimodality in EFL digital books. I will specifically talk about images (pictures and drawings), the spatial organization of the pages, and videos. In the end of this section there is a chart in which we can see the most prevalent modes in each book.

\subsubsection{Images}

Images are commonplace in textbooks. With exceptions, there are pictures and drawings in almost every page of the EFL digital books I am analyzing. Despite the apparent excess of images, these features are not simply ornaments. In this section, I will show some examples of how images are used in the books and how they interact with learning.

In the New Headway $4^{\text {th }}$ edition, the most predominant features are drawings or pictures. In the beginning of unit 6 , there is a picture of a woman called Mia. The first activity tells students to describe her; afterwards, they will listen to an interview with her. The picture allows students to start thinking of what she might be like before they listen to her speaking. The books do not always instruct students to consider the image, but students might do it spontaneously. So even if an image is connected to a written text, it is adding meaning to the text.

Another interesting use of images in the New Headway $4^{\text {th }}$ edition is on the last page of the unit. It is called "Everyday English" and it shows a page of a travel guide listing cultural activities to do in London. It seems to be taken from a real book, as it 
shows the logo of Time Out London, which is a real guide (see Figure 2). Through the visual text, students may connect to a real life situation. This is an example of a genre that originally aims to inform tourists, but now has an educational purpose.

Figure 2 - Everyday English

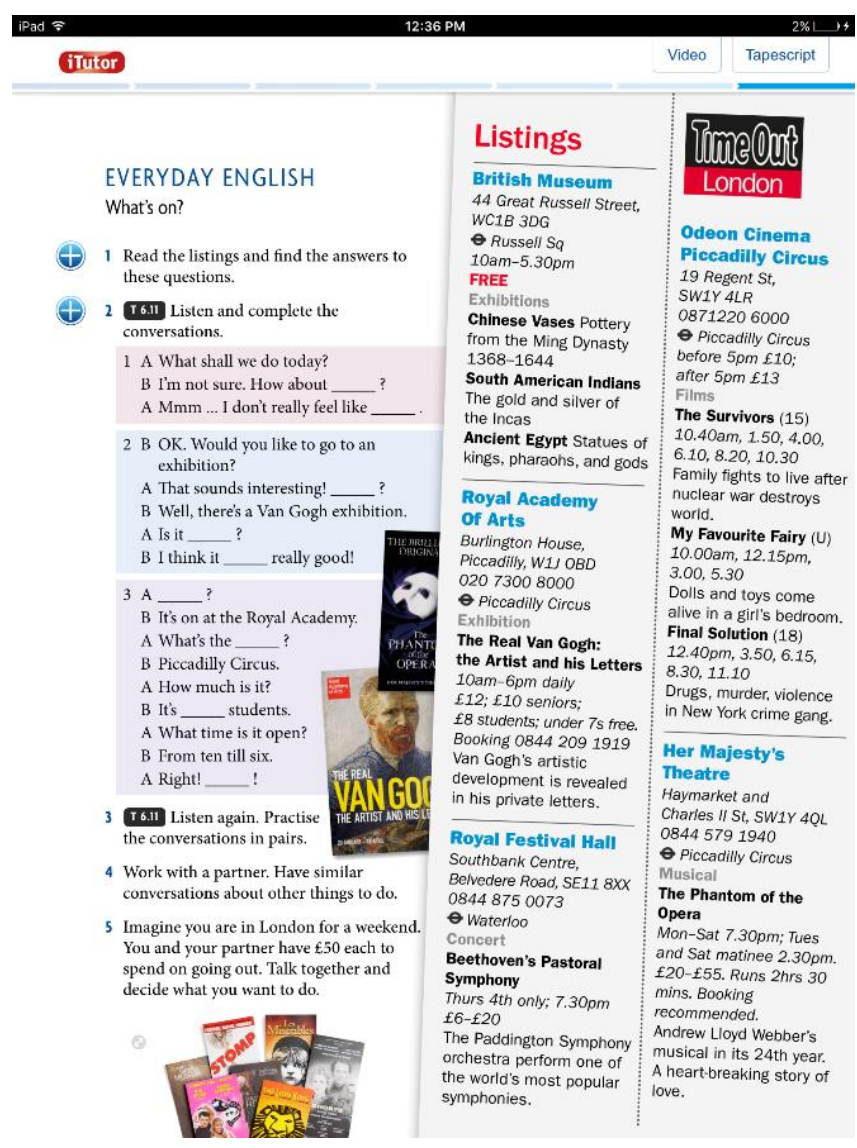

Source: screenshot of New Headway $4^{\text {th }}$ edition, p. 44

In the book Study "it" 3, images are also recurrent. In some cases, they are used to illustrate the written text and in others, to exemplify the grammar explanation. The expression, the clothes and the speech bubbles contribute to the understanding in a way writing could not do. The book also uses images to connect with the real world. In an exercise called "business trip," there is an image of a closed agenda, and, when the agenda opens, we can see some appointments in it. It is a clear reference to an object that is part of our daily life.

Pictures play different roles in the book iLook,iThink, iLearn. The first picture of each unit is connected to the introductory text and is there to exemplify it. However, in 
unit one, there is an article about an electric car, and on the following page there is a sequence of pictures of the car (see Figure 3). Differently from the picture of Mia in the New Headway $4^{\text {th }}$ edition, which is explored before the activity, here they appear after. They do not help students create an image of the car before reading the text; in fact, they show what it is unable to describe and they might contribute to changing the learners' first impression of it.

Figure 3 - The folding car

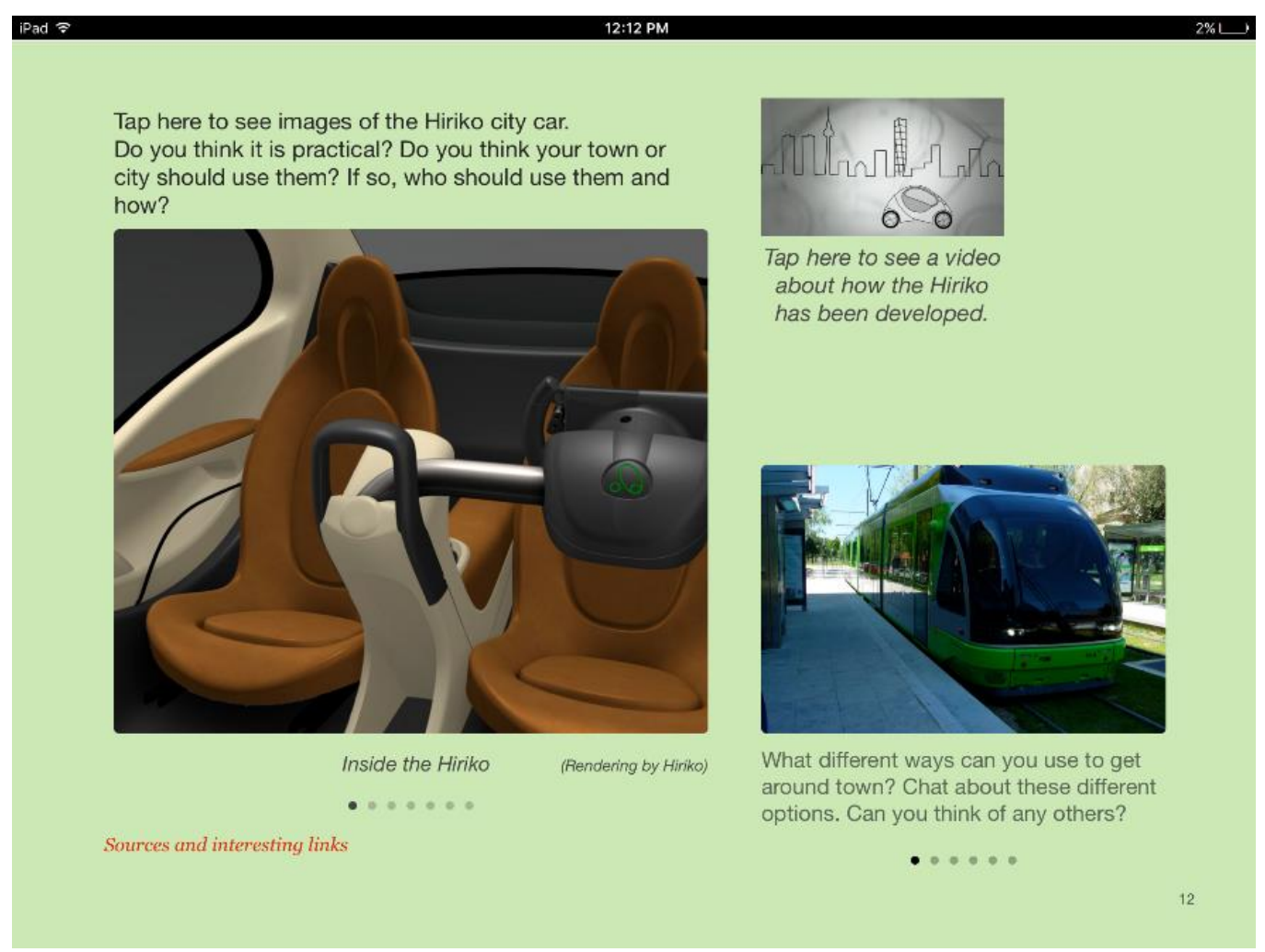

Source: screenshot of iLook,iThink,iSpeak, p. 12

In another page from the same book, students have to talk about different ways to get around town. Pictures are displayed to give some suggestions and help students by giving food for thought. By showing means of transportation which are not very common such as "cableway," the pictures may encourage students to look for what is probably new vocabulary for them.

On the first page of Breaking the English Barrier, there are pictures of important sights and people in the United States. The pictures of people such as Madeleine Albright and President Barack Obama are there to illustrate the written text. However, 
the pictures of sights might play the opposite role. These pictures show what the country is like and the text only gives the names of the places. In this case, written text would not make sense without the pictures.

The unit I analysed in this book has three sets of flashcards (see Figure 4). First, there is a card in one set with the word in Spanish, then, another set has the word in English, and the last set has a picture that illustrate the word. The way the flashcards are presented gives students freedom to engage with the text in the way they prefer. They might choose to ignore the picture in case they feel the translation is enough, or they might choose to ignore the word in Spanish and focus on the picture and the English word.

Figure 4 - flashcards

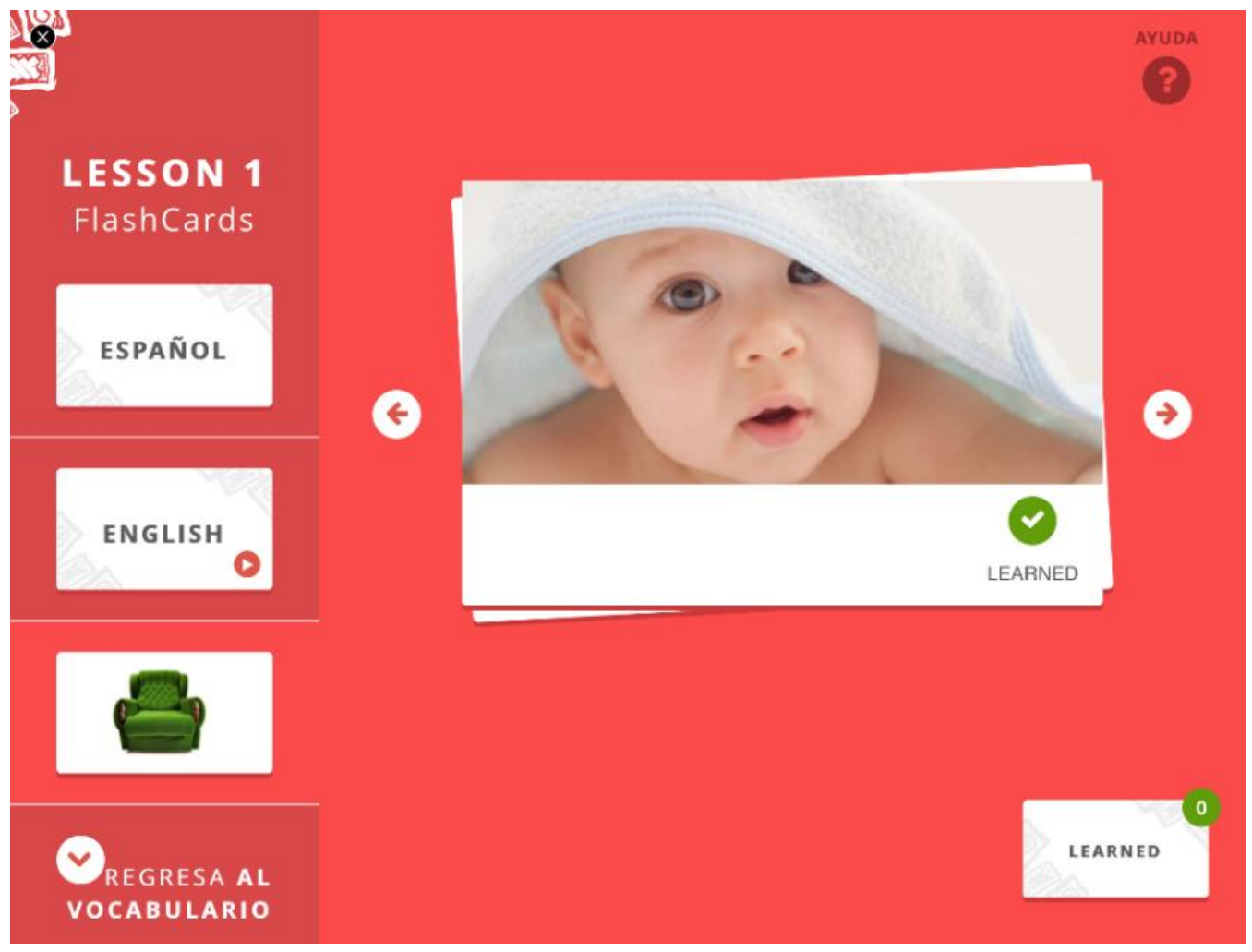

Source: screenshot of Breaking the English Barrier, p. 3

Regarding visual features, the book In class English Speaking presents an uncommon aspect, as it is full of Memes (see Figure 5). According to the website Dictionary.com, a meme is: 
" noun

a cultural item that is transmitted by repetition and replication in a manner analogous to the biological transmission of genes.

a cultural item in the form of an image, video, phrase, etc., that is spread via the Internet and often altered in a creative or humorous way."

The second definition (b) is the one I refer to when talking about memes. Nowadays, memes are very popular on social networking websites, especially among young people. Although they are considered to be a cultural item, memes are internationally used and shared online. They are part of the virtual community. These images serve to illustrate the written text as well as to connect students to a real life situation; however, the fact that the author chose a meme instead of a picture or a drawing gives the book some personification. In addition, it might be a way of telling who the book is designed for. It is informal, modern, humorous, and made for people who are connected virtually.

Figure 5 - In class English Speaking Course Book 1
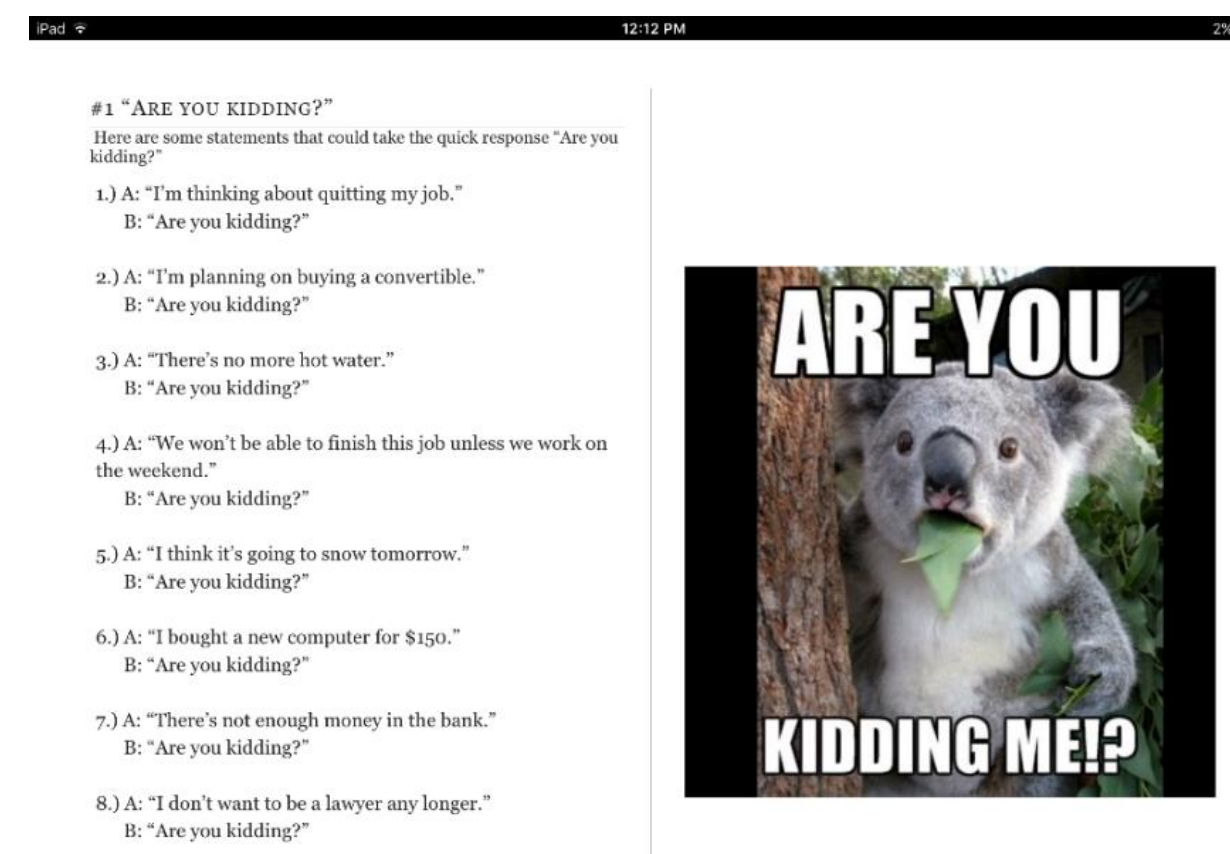

Source: screenshot of In class English Speaking, p. 4. 
UptoDate 5 has both drawings and photos. All the photos are somehow connected to a written text so their role is to exemplify them. The drawings seem to have a different purpose. They do not seem to be connected with the topic of the lessons. And at first we might think they are only filling an empty space. However, they have similar lines and show people, mostly young people, outdoors in what seems to be a big city (see Figure 6). They appear on the first page of the unit and when there are exercises. These images might not contribute to learning but are not there randomly either. They seem to be part of the book's visual identity.

The unit I analyzed in the book Learning English 4 does not contain any picture or drawing. Not adding images in a recently published book is an unusual choice. Unfortunately, I cannot know the authors' intention in doing so but it is possible that they believe students could benefit better from writing and audios. Besides this sampling, images are a weighty visual feature in the EFL digital book and play various roles. Not only do they demonstrate what written texts or audios are not able to show, they change the way students engage with the material and help the book create their own identity.

Figure 6 - Drawings in UptoDate 5

iPad $\%$

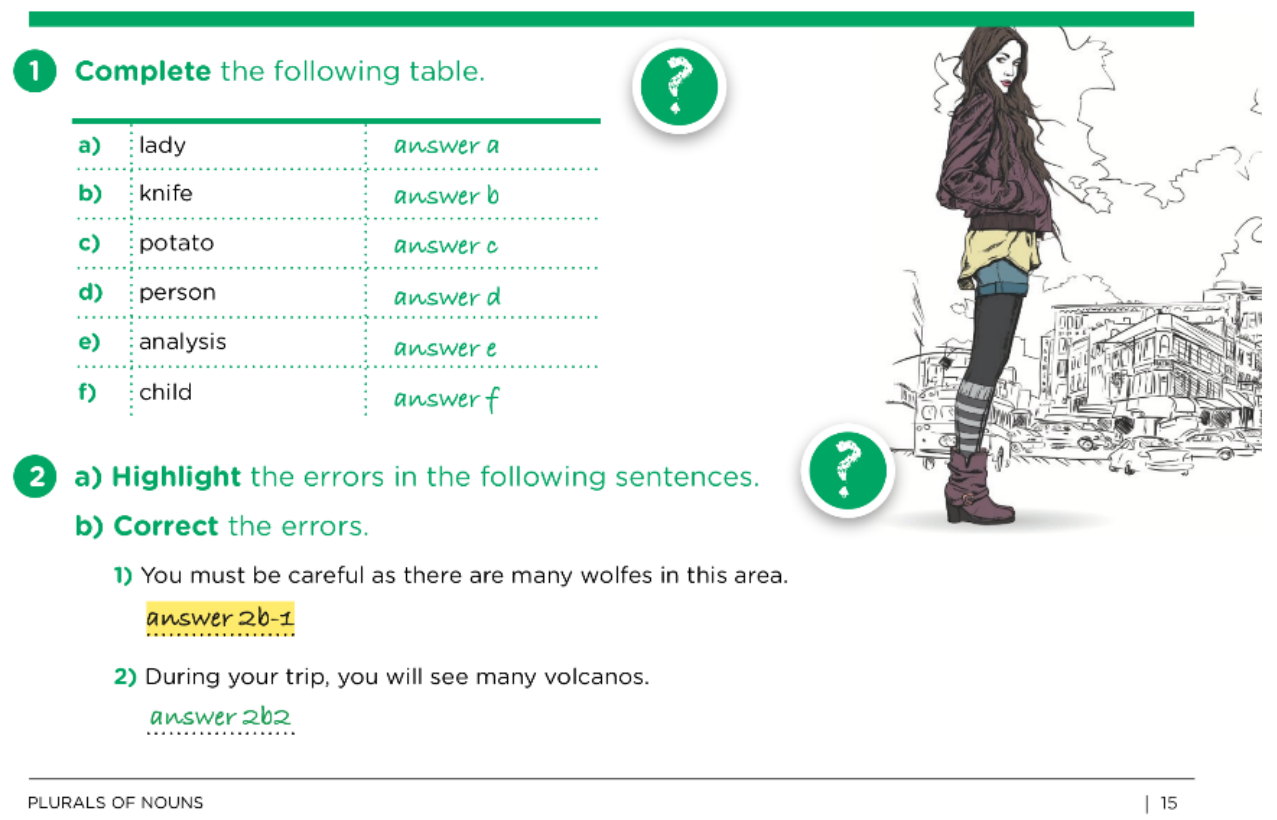

Source: screenshot of UptoDate 5, p. 15 


\subsubsection{Spatial organization}

Spatial organization refers to the design of the book and the arrangement of the elements in each page. EFL printed coursebooks have a certain regularity of spatial arrangement. Thinking about this, I believe that by looking at spatial organization I might be able to find a pattern in the EFL digital coursebooks, which can indicate they represent a sample of a genre. It would be impossible to look at every page separately, but I will give an overview of the most predominant spatial aspects of each book.

Learn English 4 (See Figure 8) is not the most visual and dynamic of the sample. It is composed by written texts and audio tracks, and the only image in it is the picture on the cover of the book. Two pages, in vertical position, fit on the screen, and the written text occupies most of the page. In order to show the division of the sections, the headings are bold and the font is bigger in relation to the other parts of the screen. The text is all in black type, with the exception of one sentence in red and one in blue, and the background is white. The layout is monochromatic, and, as a result, it does not match the book description that says "interactive" and "fun".

Figure 8 - spatial organization of Learn English 4

Innovative Language Learning, LLC

No Joking in English at Immigration!

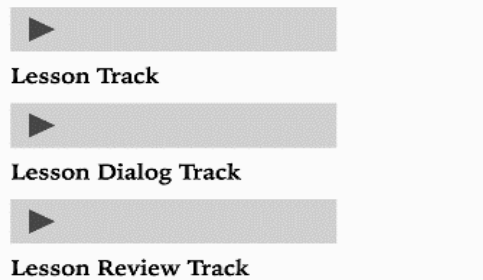

You're feeling a bit nervous: it's your first time going through immigration in the United States, and you're not sure what to expect. Your traveling companion tells you in English, "Just relax. I've done this before. It will be fine." You ask your friend in English, "But what if the man asks me a ton of questions? I'm not from America, so what if he thinks I'm a terrorist?" Your friend looks you up and down and says in English,
Learn English - Level 4: 1...glish (Enhanced Version)

"The immigration officer isn't going to think someone in a bright pink, floral-printed sundress is a terrorist. Just answer whatever questions the officer asks, and whatever you do, don't say the English words 'terrorist,' 'bomb,' or 'knife.' Think you can handle that?" You respond in English, "I'll just say 'Yes, sir' and 'No, sir." Your friend reminds you in English, "That's fine if we're not in line with the female officer; if we are, I would recommend that you call her ma'am!"

This English Intermediate lesson will teach you how to structure sentences using the English conditional words "if" and "would." We'll also tell you some helpful hints on how you can make traveling through immigration when you arrive in the United States as painless as possible. Visit our site where you will find many more fantastic English lessons and learning resources! Leave us a message while you are there!

Line-By-Line Transcript

Source: screenshot of Learn English, p. 9 
In class English Speaking Course Book 1 does not use colors either, but it differs from Learn English 4 in terms of the use of images and the text organization. This is one of the few books which I was able to download entirely and not only one chapter. What is peculiar about it is that every chapter has the same organization and begins with an overview page that presents the content of the unit and a photo of a classroom in which students are using computers. The following pages are divided into two columns. The text on every page is not written in paragraphs but presented in topics and numbered. There are two multiple choice exercises in each chapter and there is an image (meme) on the fourth page (see Figure 5). It ends with a writing activity, and all the units have five pages.

Figure 5 - In class English Speaking Course Book 1
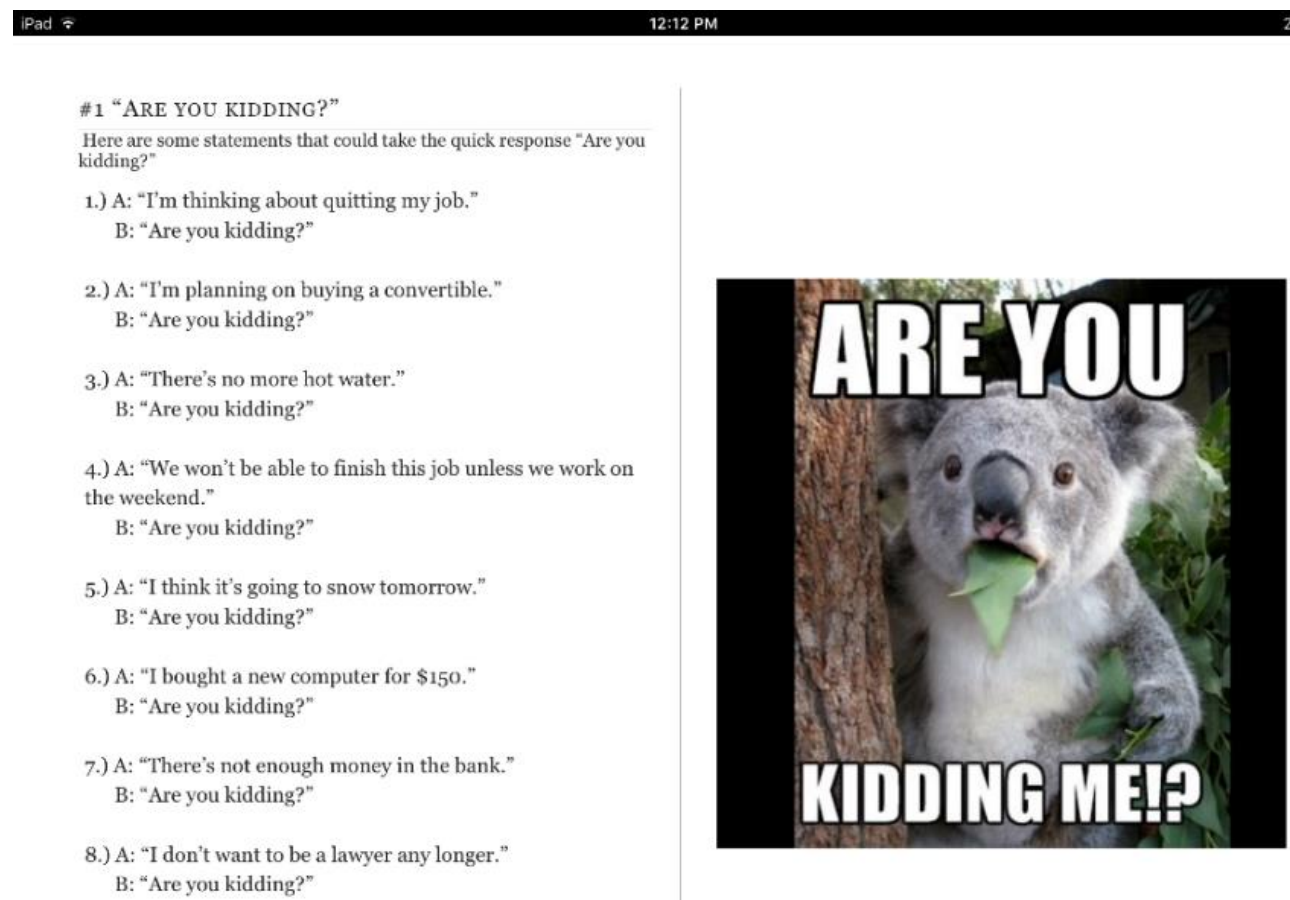

Source: screenshot of In class English Speaking, p. 4.

Estudy"it" 3 uses strong colors which give the book a modern, dynamic look. Every page in this book is different, so there does not seem to be a pattern in its structural organization. There is one common feature, a green stripe at the top of the 
pages with the name of the section on it. This gives us the sense of continuity throughout the book. The first page of the unit I analyzed is divided into four parts. It has a video of a job interview, a speaking activity in which students are encouraged to talk about themselves, a vocabulary list and a video comprehension exercise (see Figure 9 below). Since there are no instructions, it is not clear what the preferred order of activities is and whether there is an order at all. This non-linear design gives the teacher or students freedom to interact with the book in the way they find more convenient. Each individual will have have their particular engagement with the book.

Figure 9 - spatial organization of Study"it"

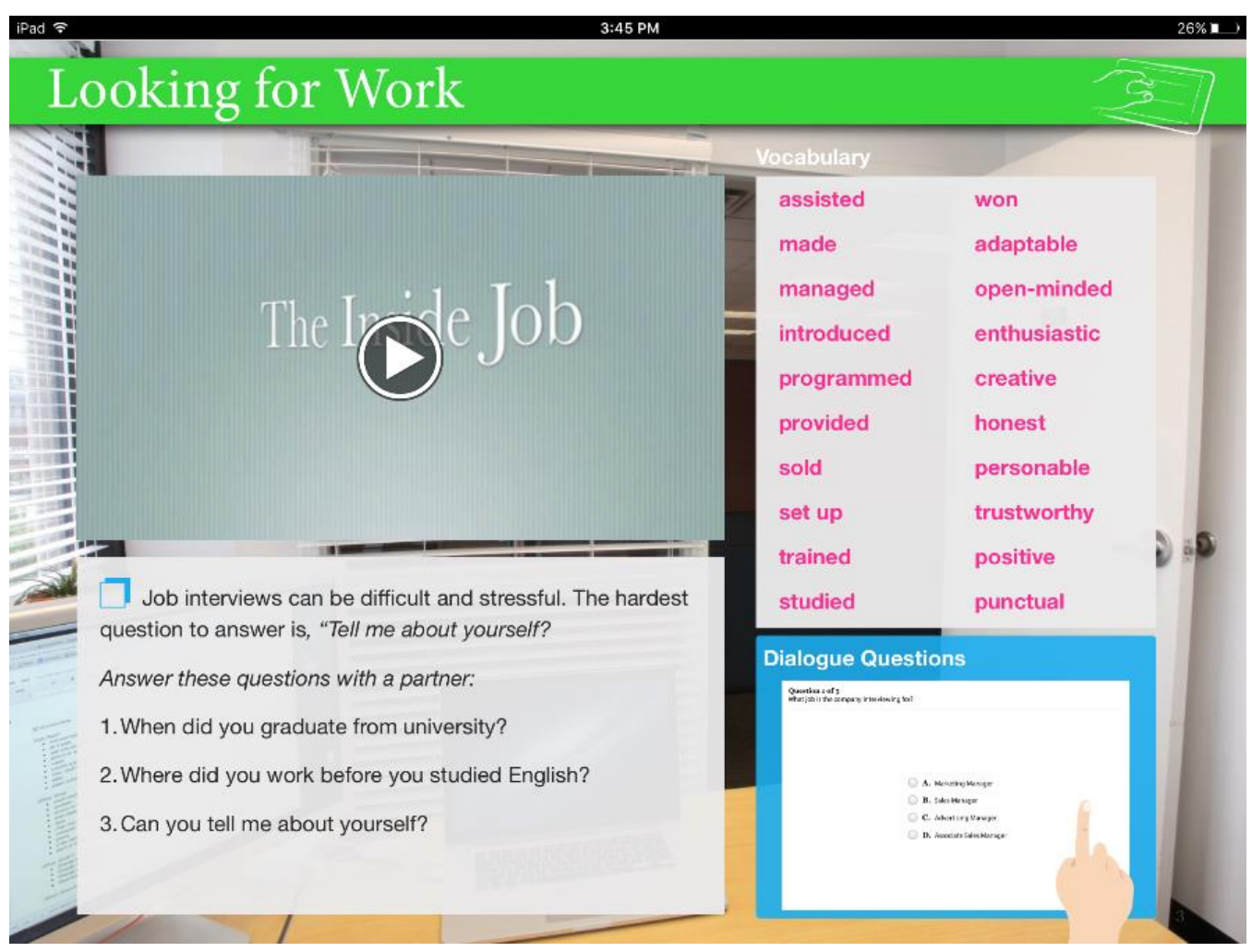

Source: screenshot of Study"it”, p. 1

Similarly, Breaking the English Barrier begins the chapter with several items of information about the United States, including 17 pictures of important sights, a map indicating its capital, photos and a brief profile of some influential people and a rightside column that shows the photo of the current president Barack Obama and below it some information about the country such as population, currency and language. Once 
again, each person will engage with this page in a particular way. All the information seems to be equally important, and there are no instructions about what to do there. One learner might choose to go through all the pages while another might ignore the whole page.

The layout of the book is colorful with predominance of pink, white and grey. It also has an arrow on the top of each page that indicates the number of the chapter. Explanations are presented on a white background while exercises are presented in a grey chart on top of a reddish background. Only by the end of the unit does the layout change, when we see an article about Broadway. In the background, there is a picture of a busy street in New York, and the headline imitates a Broadway show sign, surrounded by light bulbs (see Figure 10). These changes indicate that this is a new section of the book, and they also boost the visual aspect of the article. If students are not familiar with this place, the heading and the background will tell them what it is like, even before they read the text. The visual elements here add to the text details that cannot be described in writing.

Figure 10 - Breaking the English Barrier layout

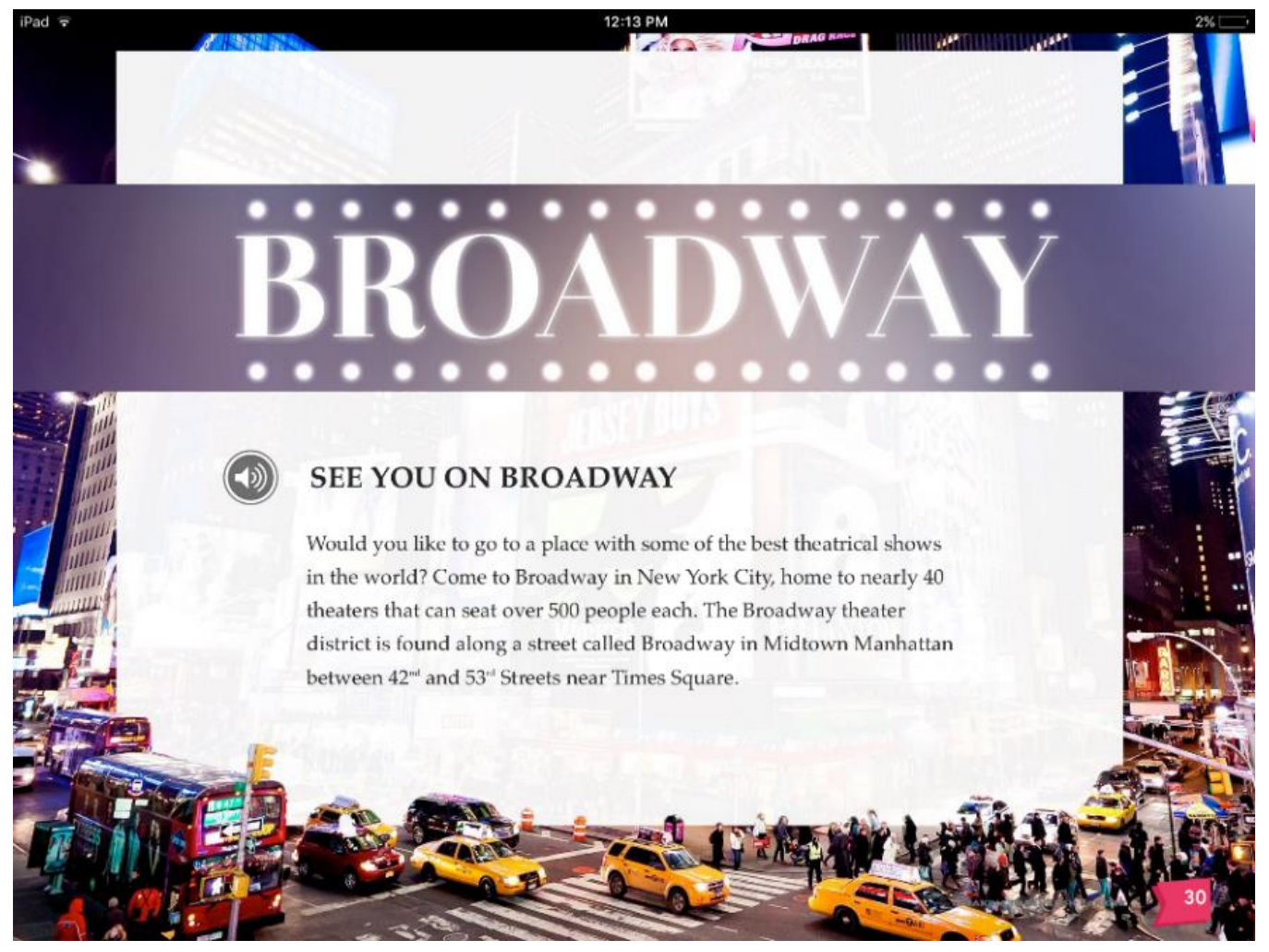

Source: screenshot of Breaking the English Barrier, p. 30. 
The New headway $4^{\text {th }}$ edition has a feature that distinguishes it from all the other books. It should be read in the vertical position while all the others are read horizontally. (Only Learn English 4 offers the choice of reading in both vertical and horizontal position showing one or two pages). This book is the only one that is not exclusively digital, so we might assume it follows the same layout of its printed version. However, most of the content we see on the pages is images and instructions (see Figure 11). That is because both explanations and exercises are minimized and only appear when clicked on. An important characteristic of digital EFL books is that not all content is visible.

Figure 11 - New Headway $4^{\text {th }}$ edition

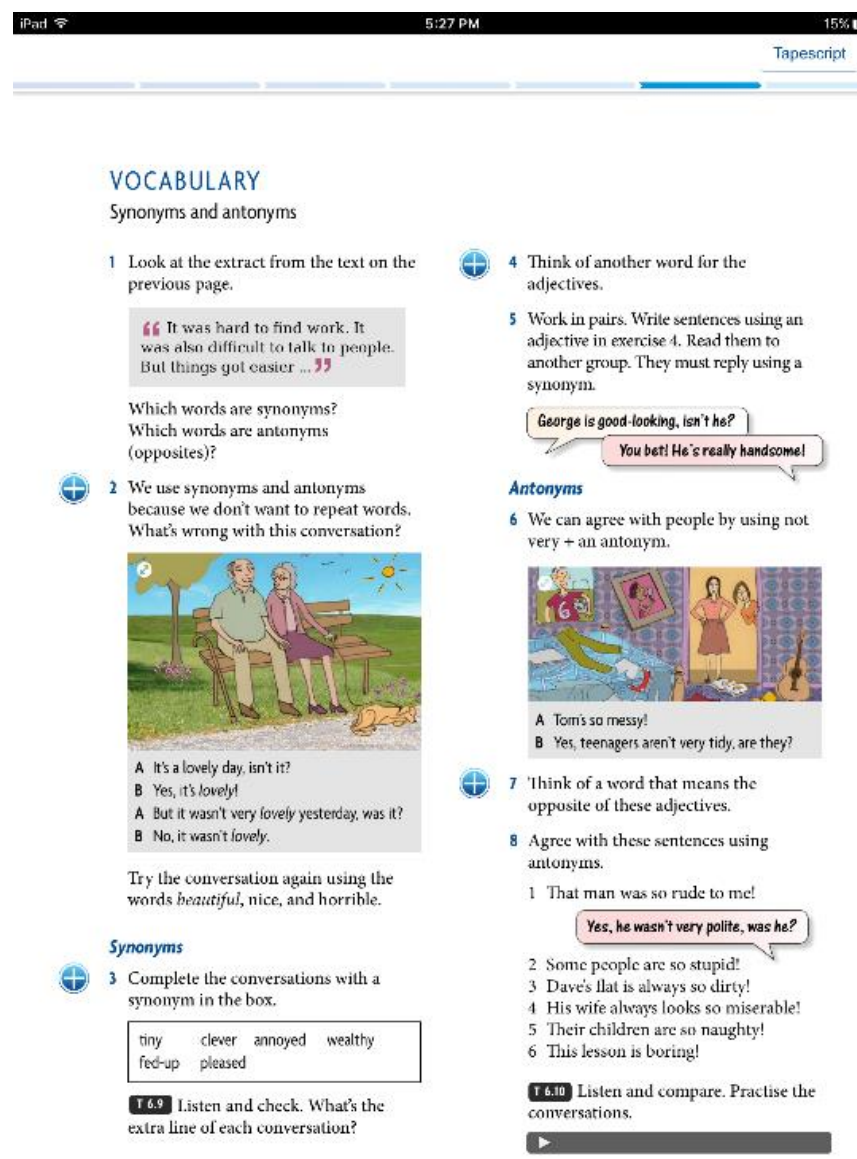

Source: screenshot of New Headway $4^{\text {th }}$ edition, p.43.

UptoDate 5 is also a colorful and dynamic book. I noticed that the explanation pages are green while the exercise pages are white. The choice for a neutral color is 
conductive to paying attention to the exercises. Every explanation page has a chart that says: "watch out for common mistakes" and this chart is indicated by a yellow exclamation mark. The authors probably consider this an important aspect, so they use these features (exclamation mark, bright color) to call learners' attention (see Figure 12). I did not perceive any pattern in the exercises. Sometimes they are within a chart that occupies the whole page, sometimes they share the screen with a drawing, and other times they are minimized within a page and they expand when we tap on the tab.

Finally, the book iLook, iThink, iSpeak also gives an overview of the unit on the first page. This book focuses on written texts and they occupy a large part of the screen (see Figure 13). The page that follows each text varies according to the activity proposed although the appearance does not change much.

Figure 12 - Watch out for common mistakes

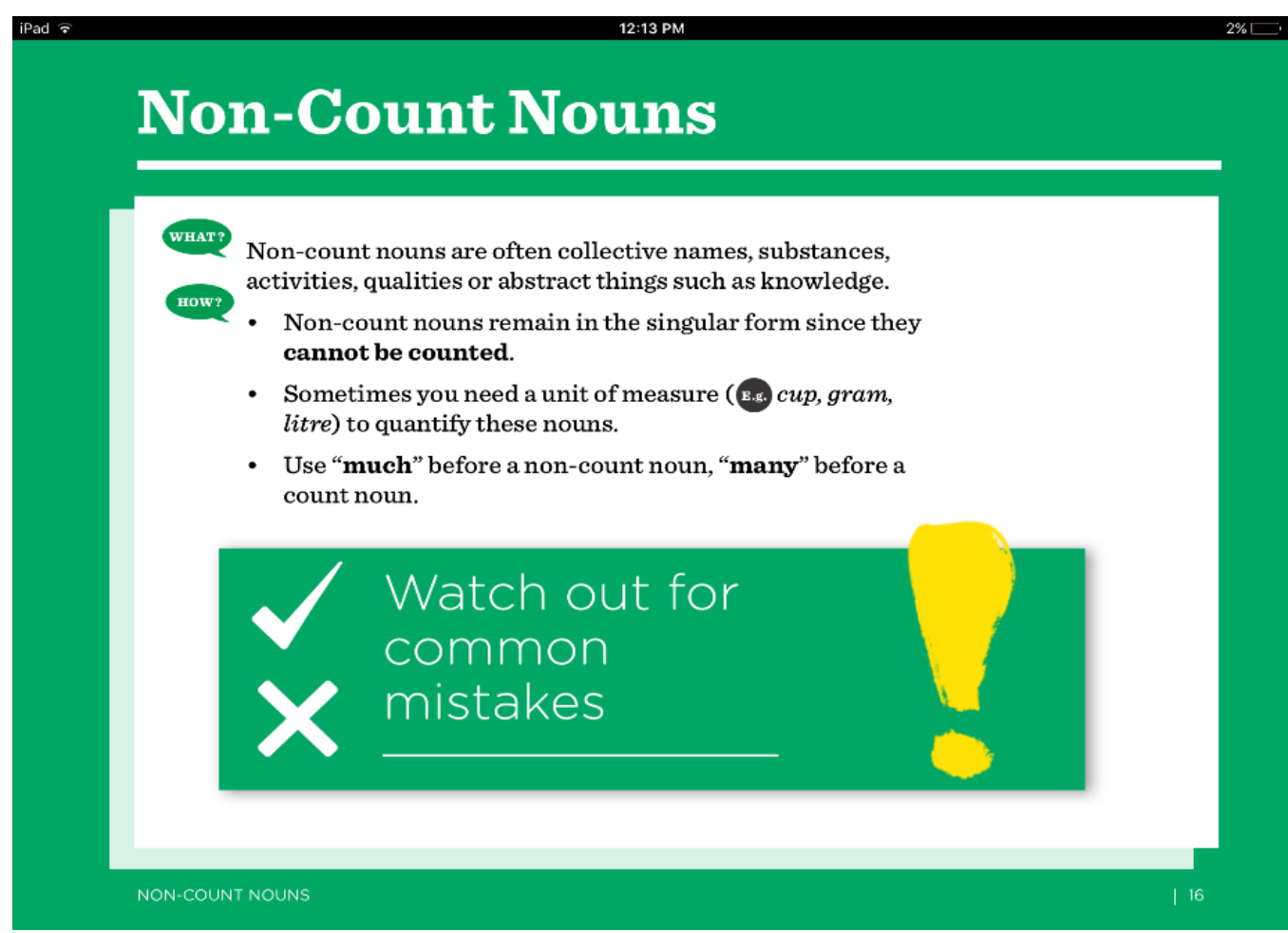

Source: screenshot of UptoDate 5, p. 16. 


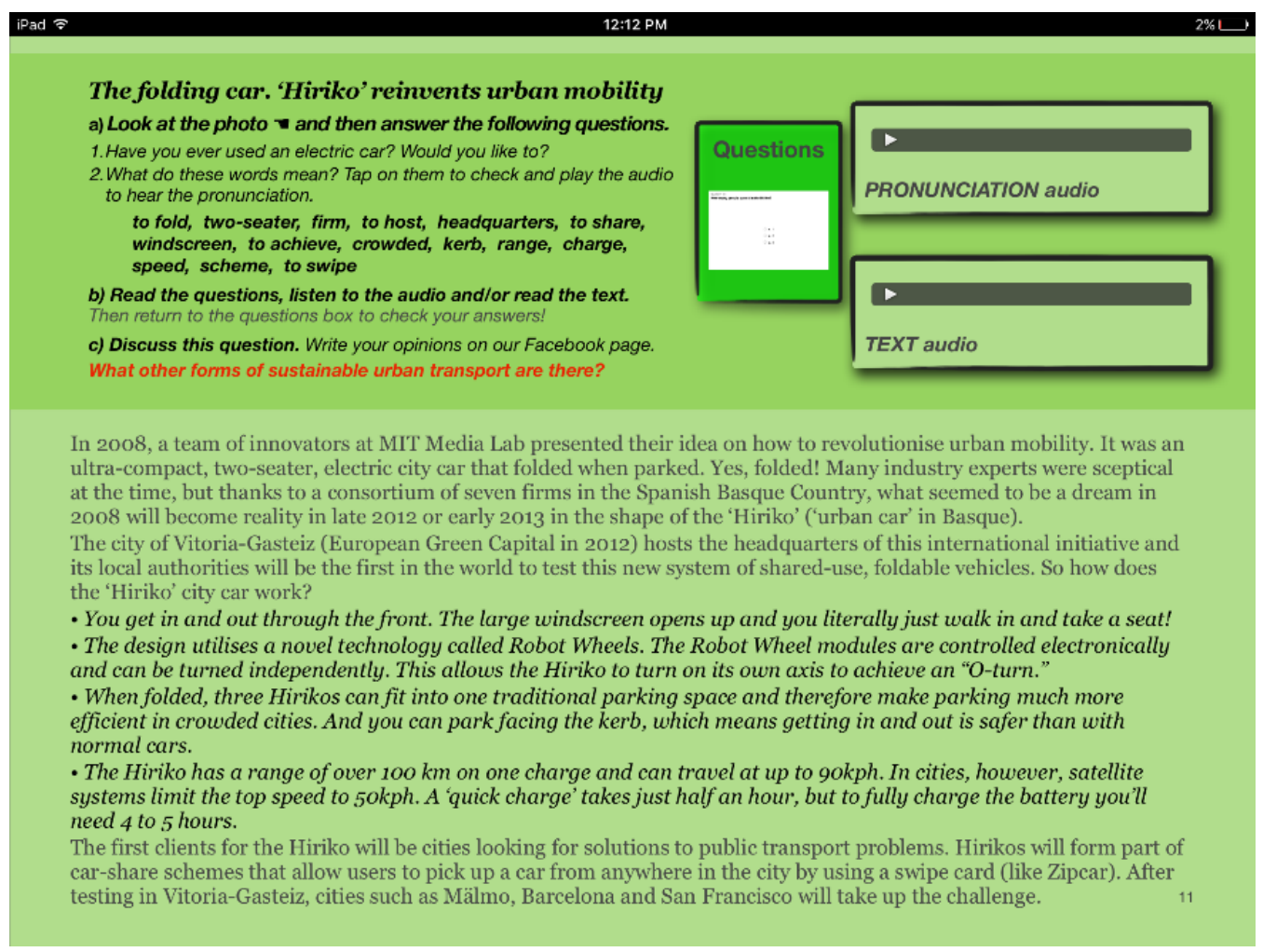

Source: screenshot of iLook,iThink,iSpeak, p. 11

Chapter one contains two sets of pictures and a video. The first set of pictures occupies half of the screen, which might show the importance they have. These pictures are in fact connected with a speaking activity, whereas the video serves to complement the article and the images. The book also makes use of colors to indicate each lesson; for example, in the first lesson, the background is blue, in the second it is green.

What stands out from the analysis is that six out of seven books use colors or different backgrounds to indicate a change in section or to show continuity. One book uses fonts to indicate these changes. Five out of seven books are designed in the horizontal position, one in the vertical, and one can be read in both positions. Three books offer, on some of their pages, freedom to engage in different ways by not giving instructions or prioritizing one element over another. Five books contain click-on exercises that are minimized and do not occupy much space on the screen, but when expanded occupy the whole screen. Each book has its own individual characteristics regarding spatial organization. Some books are more dynamic, that is, they show more 
variation in their spatial organization, whereas others show a higher regularity in their appearance. One book is highly regular and follows the same standard in every unit. Thus, if we consider whether there is a standard treatment of space among these books, we will take into account not only their looks but also the mobility of the device that allows for new tabs to be open, or change the position of the page. What we have seen is that there are no standards for the spatial structure of the EFL digital books.

\subsubsection{Videos}

It is not rare to find mainstream coursebooks that are accompanied by a DVD that contains videos related to the lessons. There may also be a page in the book called a video activity with ready-made activities to explore the video. In the EFL digital books I analyzed, videos are not predominant. Moreover, they seem to be playing a different role than in standard printed books.

ILook,iThink,iSpeak contains a video presentation that complements an article students read in advance. There are no comprehension questions about the video. Instead of having a language purpose, the video aims to help students form their opinion about the car, and it is connected with the article and some pictures. It also aims to connect students with the real world. This video does not look like it was made for the coursebook but actually taken from a website. I cannot be certain about this because, though it cites the sources which were used to develop the lesson, I could not find the video in any of the links. However, the video shows the actual inventors of the car talking about it and real cities where the car is being used.

Breaking the English Barrier uses a video in a similar manner. After a text that talks about Broadway, it presents a video showing plays, billboards, people walking around Manhattan and some street performances while there is jazz playing in the background. On the following page, there are some questions about Broadway. Students are able to answer these questions without the video, but the book gives students another option to engage with the text and learn about the place.

Differently from the other books, Study"it" begins with a video and a comprehension exercise about it. The topic of the lesson is Looking for work, and the 
video is a job interview. So I believe it has two different functions: having students practice their receptive skills as well as contextualizing and introducing the lesson. Later in the unit, there is a second video which shows people answering questions about where they have worked. There are no questions about the video, but there is a speaking activity in which students have to answer similar questions. The video is there to serve as a model and prepare students to talk. Unlike iLook,iThink, iLearn, both videos in Study"it" seem to have been made for the purpose of the publication. One of the actors even appears in both videos.

Aside from the digital books mentioned above, none of the others carry videos in their content. That is, only three out of seven books use videos and only one or two videos per unit. This is a comparably low number if we think of the amount of images that appear in each book. These videos, though, serve various functions. They test students' comprehension skills, contextualize the lesson, exemplify activities, connect students with the real world, and change the way students engage with the material.

Multimodality has an important role in EFL digital books. Modes collaborate to meaning making in the text. In this section, I analyzed images, videos and spatial organization in order to check how they affect learning and whether those books have similar characteristics that could classify them as a genre. Images are a frequently used resource in digital coursebooks while videos are rare. Most books are designed to be read in the horizontal position. Some books show a more dynamic layout with high variation in spatial organization from page to page while others are more consistent in their appearance. The chart below (Figure 14) shows differences and similarities found in the analyzed digital coursebooks. 
Figure 14 - Visual Resources

\begin{tabular}{|c|c|c|c|c|}
\hline Books & $\begin{array}{l}\text { Number of } \\
\text { Images }\end{array}$ & $\begin{array}{c}\text { Number of } \\
\text { Videos }\end{array}$ & $\begin{array}{l}\text { Layout of } \\
\text { pages }\end{array}$ & $\begin{array}{c}\text { Position of } \\
\text { page }\end{array}$ \\
\hline $\begin{array}{c}\text { NEW HEADWAY } \\
\text { Pre-intermediate } \\
\text { 4th edition }\end{array}$ & 20 & 0 & $\begin{array}{l}\text { Dynamic, } \\
\text { colorful, Layout } \\
\text { chages often }\end{array}$ & Vertical \\
\hline $\begin{array}{c}\text { iLook, iThink, } \\
\text { iSpeak English } \\
\text { Practice - } \\
\text { Technology }\end{array}$ & 15 & 1 & $\begin{array}{l}\text { Colorful, Layout } \\
\text { is consistent , } \\
\text { writing is } \\
\text { predominant }\end{array}$ & Horizontal \\
\hline $\begin{array}{c}\text { Learn English - } \\
\text { Level } 4\end{array}$ & 0 & 0 & $\begin{array}{l}\text { Layout is } \\
\text { consistent, } \\
\text { monochomatic, } \\
\text { writing is } \\
\text { predominant }\end{array}$ & $\begin{array}{c}\text { Vertical and } \\
\text { horizontal }\end{array}$ \\
\hline Study it 3 & 21 & 2 & $\begin{array}{l}\text { Dynamic, } \\
\text { colorful, layout } \\
\text { change often }\end{array}$ & Horizontal \\
\hline $\begin{array}{c}\text { Breaking the } \\
\text { English Barrier } \\
\text { Level } 1\end{array}$ & $\begin{array}{c}102 \\
49 \text { images } 53 \\
\text { flash cards }\end{array}$ & 1 & $\begin{array}{c}\text { Dynamic, } \\
\text { colorful, layout } \\
\text { change often }\end{array}$ & Horizontal \\
\hline $\begin{array}{c}\text { In Class English } \\
\text { Speaking Course } \\
\text { Book } 1\end{array}$ & 4 & 0 & $\begin{array}{l}\text { Layout is } \\
\text { consistent, } \\
\text { monochomatic, } \\
\text { writing is } \\
\text { predominant } \\
\text { and in topics }\end{array}$ & Horizontal \\
\hline UptoDate 5 & 17 & 0 & $\begin{array}{c}\text { Dynamic, } \\
\text { colorful, layout } \\
\text { change often }\end{array}$ & Horizontal \\
\hline
\end{tabular}




\subsection{Approach to grammar}

In order to carry out the analysis of grammar presentations, I used some criteria proposed by Ur(1991) and by Swan(2006). These criteria are: comprehensibility and acceptability, clarity, simplicity, focus on form vs. focus on meaning, and use of digital resources as a contribution to innovative ways of approaching grammar. Each of these criteria will be presented in a separate section.

\subsubsection{Comprehensibility and acceptability}

The concepts of comprehensibility and acceptability are in opposition to each other. The first one is concerned with efficient communication rather than accuracy. The second concept is concerned with the pressure the learners undergo to speak accurately and be accepted on the same terms as a native speaker. These concepts are subject to the teacher's beliefs and choices, though in the description of some books we have evidence of the authors' intentions. For instance, the book Breaking the English barrier describes itself as a "path to total fluency" and Learn English level 4 promises to "arm you with English and cultural insight to utterly shock and amaze your English friends." This is clearly a focus on acceptability. Most books seem to be concerned with correctness and accuracy; at the same time, some books reveal the view that becoming fluent is a process that demands some time. Breaking the English Barrier says that "the goal of this text is to help native Spanish speakers learn English, building confidence - step-by-step - on the path to total fluency".

The book In class English Speaking Course Book 1 does not present a grammar section; instead, it introduces language as "chunks" (see figure 15). Chunks are groups of words that go together such as idioms, collocations and verb patterns. In this book there are some very informal language items such as "dunno" as in "I don't know". This book aims to teach common expressions of the English language and help students sound like a native speaker. We may say it has a lexical approach rather than a grammar approach. Another book that does not have a grammar section is iLook, iThink, iSpeak English Practice. The lessons are based on texts which can be 
both read and listened to, and by the end of each unit students should be able to talk about the topic. In order to do that, the book provides a section called "tips for speaking", where it is written that the section aims to "help you express yourself as well as possible when speaking English" (see figure 16).

Figure 15 - In class English Speaking Course Book 1 language presentation

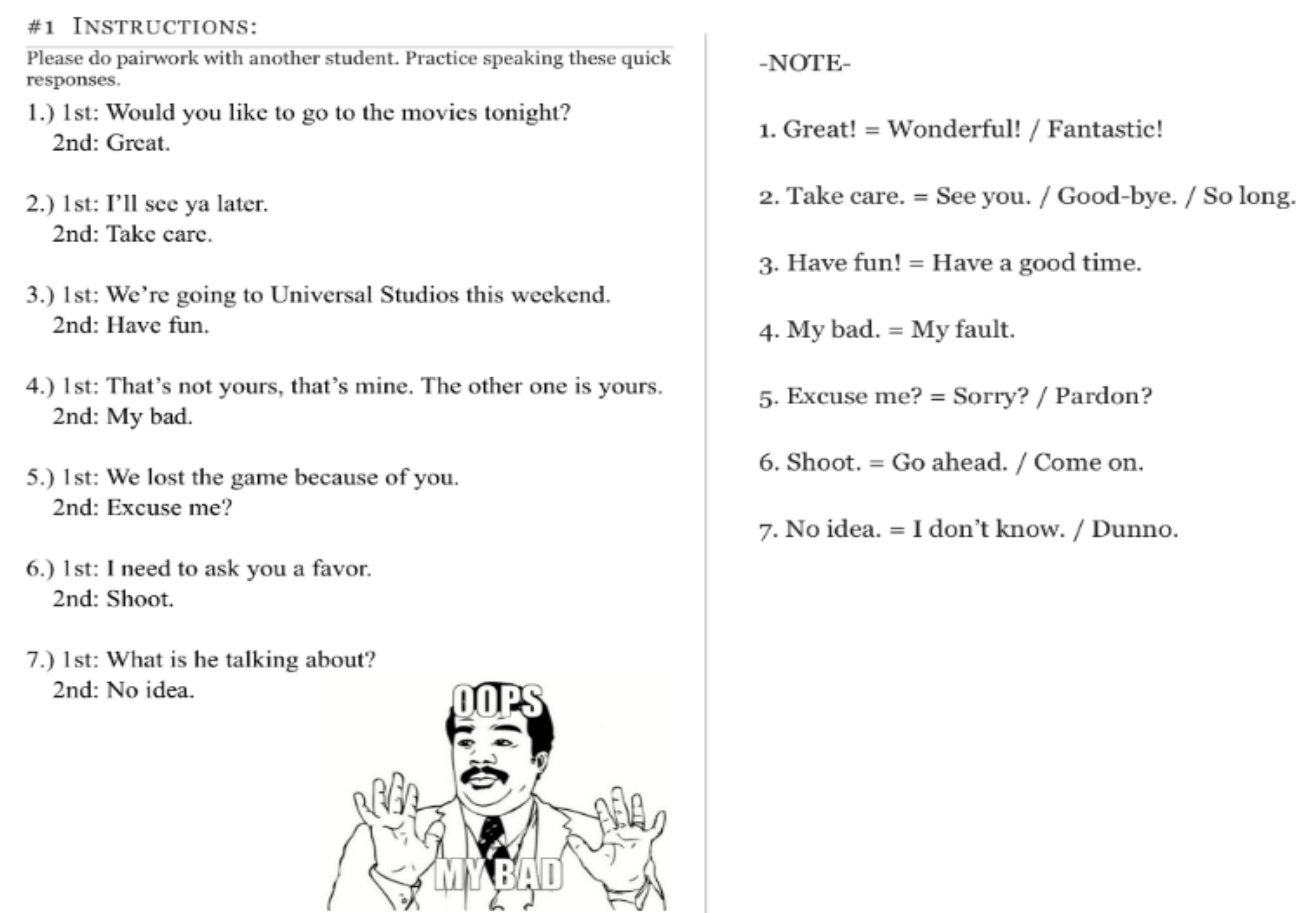

Source: screenshot of pages 1 and 2.

Differently from the two books mentioned above, the other five books have a grammar section and they introduce meaning, use and form. The importance given to each of these aspects of grammar varies from book to book, and I will address this further on in the analysis. Also, I will not talk about all five books, to avoid repetitiveness. As an example, in Study"it" 3, the grammar section begins with a presentation of the present perfect. It uses explicit explanations of the use of this verb aspect, contextualized examples, timelines and charts to explain the structure (see figure 17). It shows that the authors are concerned with making the grammar topic understandable and with being accurate. 
There may be an explanation for the lack of explicit grammar presentations in some of the books. It is possible that In class English Speaking Course Book 1 and iLook, iThink, iSpeak expect that the lessons will be studied with a tutor who will be responsible for explaining the language to students; that is, the tutor will work on understanding. Or they might assume students already have some knowledge of English and that justifications are not needed. Unfortunately, I would only be able to answer this question by asking the authors directly. Although limited, the analysis of the materials themselves shows that two books focus strongly on acceptability while five books consider both acceptability and comprehensibility in their approach to grammar.

Figure 16 - Tips for speaking

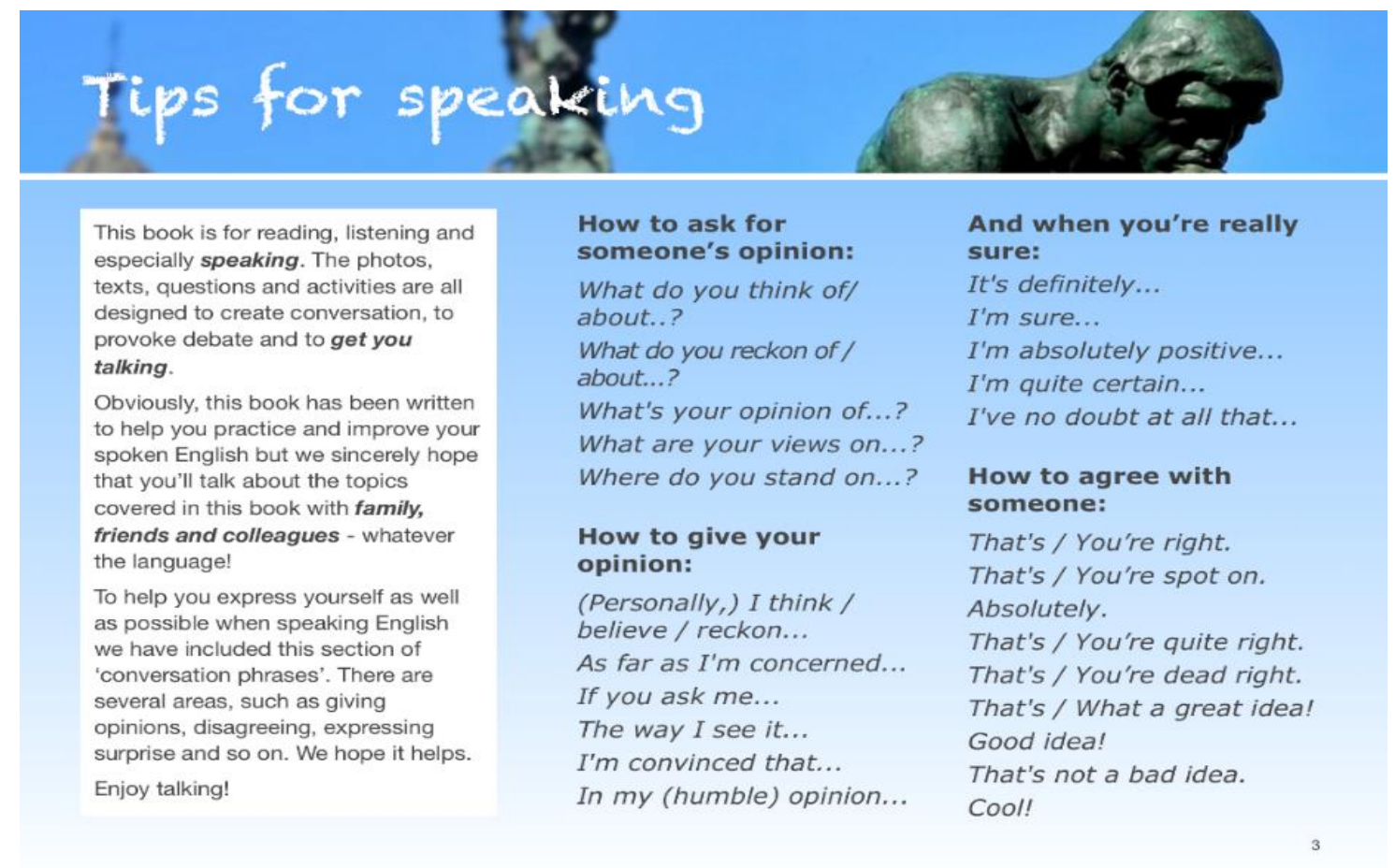

Source: screenshot of page 7 . 
Figure 17 - Study “it” 3 grammar presentation

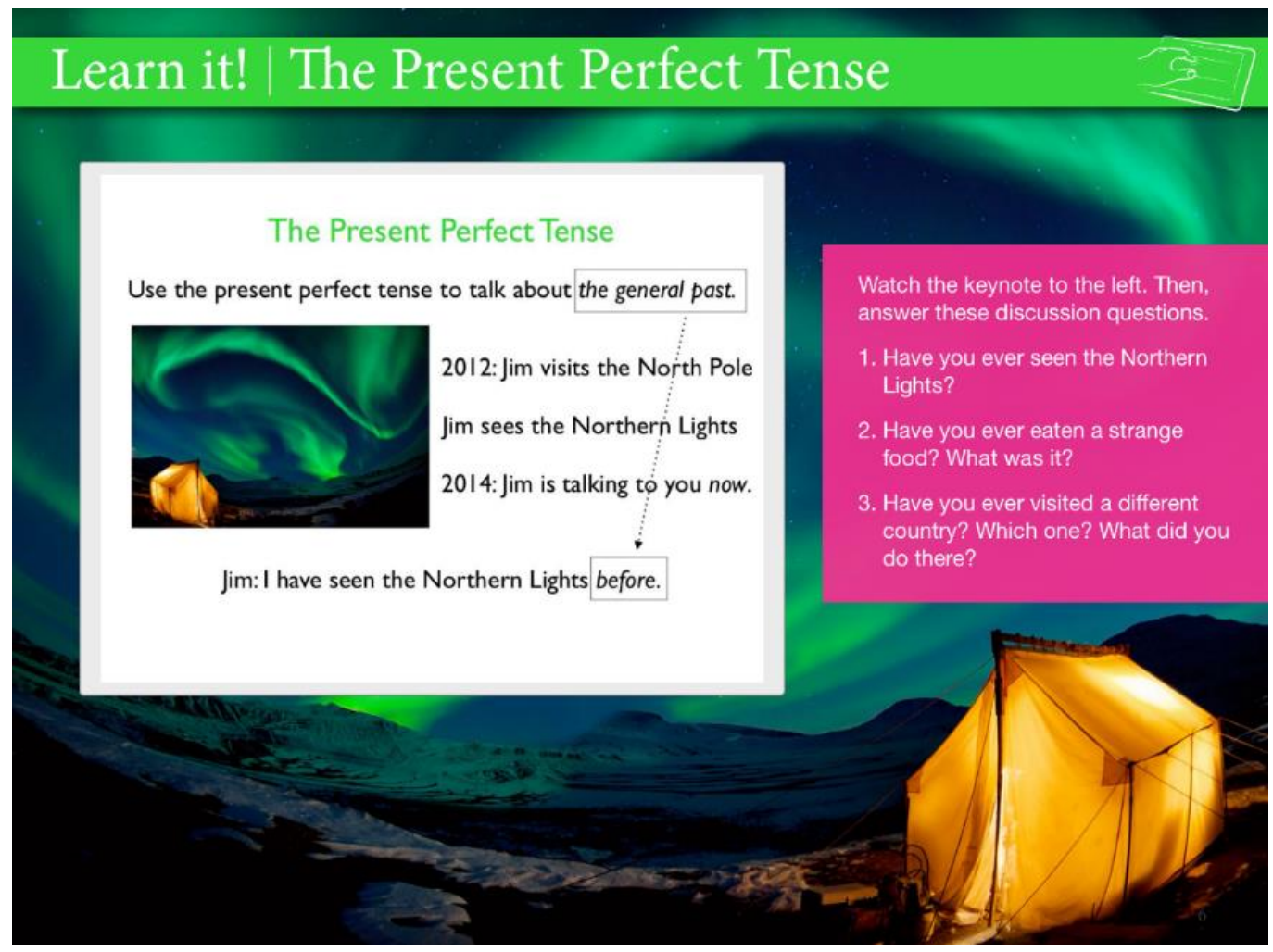

Source: screenshot of page 6.

\subsubsection{Clarity and Simplicity}

Grammar explanations should be clear and simple. These notions are similar to the concept of comprehensibility seen in the last section. The major difference is that previously we analyzed the intentions of the authors when they introduce grammar. In this part of the analysis, I will discuss how the authors managed to make grammar understandable and uncomplicated. It is important to keep in mind that clarity and simplicity can clash with accuracy (as does comprehensibility). I do not mean to say that accuracy is not an important notion; however, for my purpose, a clear, simple and short grammar explanation rather than a detailed and rigorous one will be preferable.

The book Study"it" 3 attempts to show a simplified grammar explanation. Unit 3 , for instance, teaches the Present Perfect, a verb aspect that can be used in several situations in English. The book chose to present only one: how to talk about past experiences. It opted to generalize a rule in order to make this difficult topic easier for students. In addition to that, the grammar section begins with some questions for the 
students to build the context. Contextualization is a positive contribution to clarity. Despite giving attention to clarity and simplicity, in the same unit the book addresses the use of been and gone (see figure 18), a semantic difference that could be confusing and change the meaning of a sentence. We may say that there is a balance between simplicity and accuracy. The explanation makes it simple by introducing the use of present perfect in only one situation rather than several, but still assures students will use the verbs correctly. This balance is desirable specially for more complex grammar points.

Figure 18: Verbs in the past participle

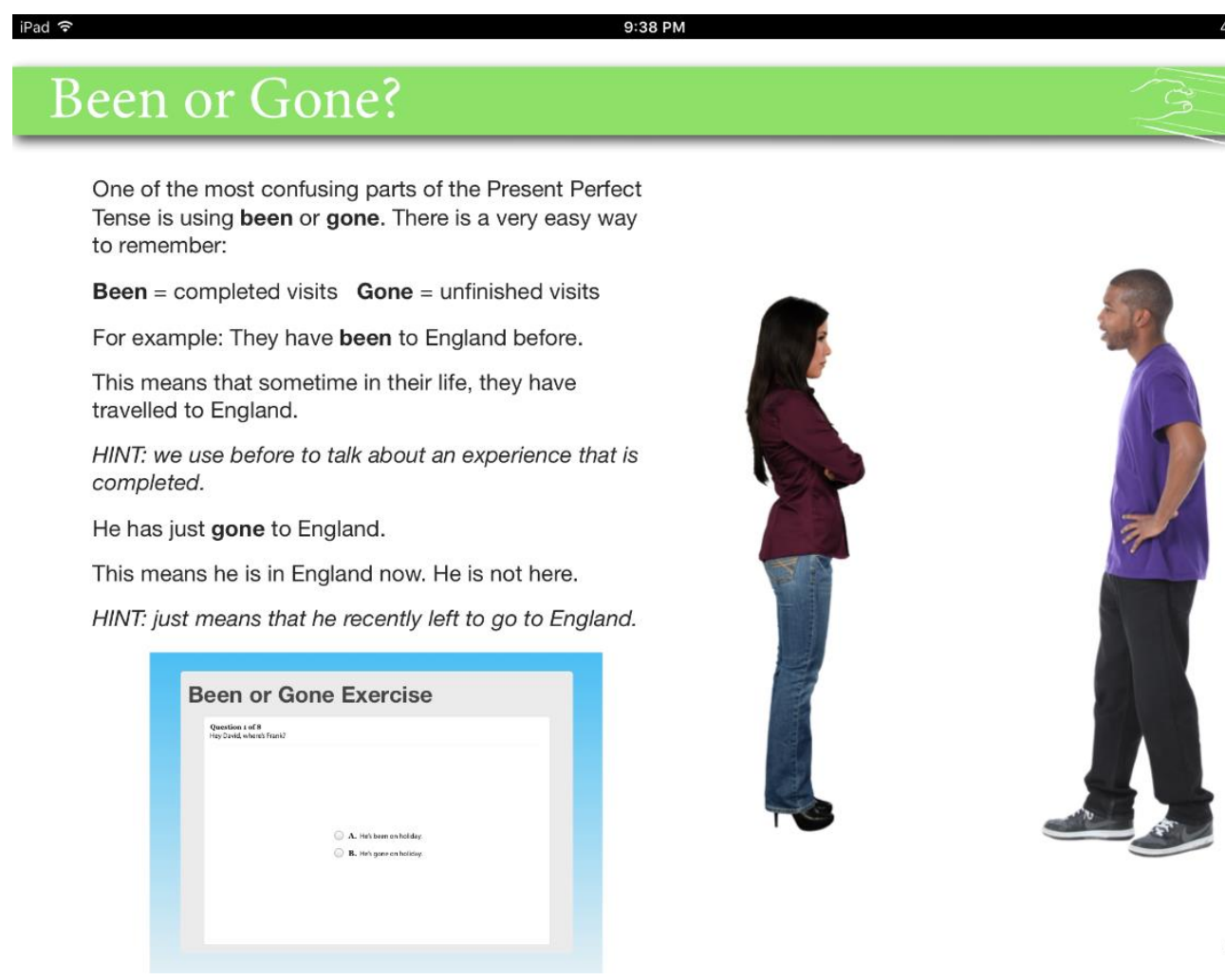

Source: screenshot of Study "it" 3 p. 14.

The book Learn English 4 is an example of oversimplification. Unit one aims to teach the second conditional, by defining it as "when talking about things that are not real or not probable" (see figure 19). The grammar section in this book is linked with a dialogue from the previous section, so students might be able to grasp the meaning of this conditional form. Still, this is not a simple topic and perhaps students could benefit 
from a more detailed explanation. UptoDate 5 and Breaking the English Barrier have two aspects in common. Both choose to present grammar as lexical units and neither of them contextualize the language. UptoDate 5 brings a number of rules about word formation and presents descriptive explanations of what are nouns, compound nous and countable and uncountable nouns, all in the same chapter. Breaking the English barrier might be more successful in terms of clarity since it approaches grammar in a different language. The book description says it targets native speakers of Spanish, and, for the sake of clarity, the grammar explanation is presented in the students' mother tongue (see figure 20).

Figure 19: Oversimplification

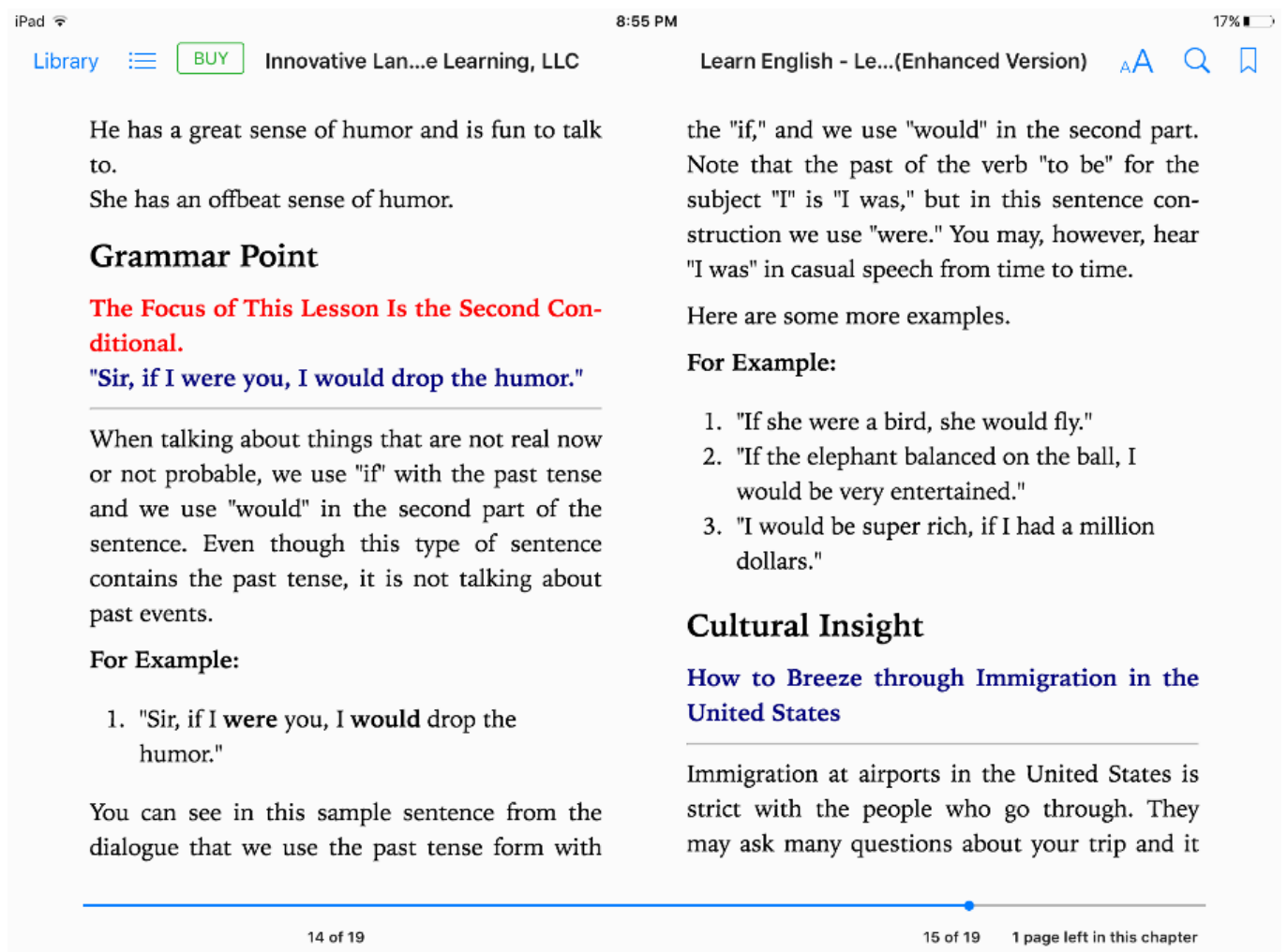

Source: screenshot of Learn English 4 p. 14.

The New Headway 4th edition presents grammar within a context and it uses a chart to work on the structure. It has a separate grammar section which I believe brings further details on meaning and use. Unfortunately, I do not have access to this section 
so I cannot affirm this. At last, the books iLook, iThink, iSpeak and In class English Speaking Course Book 1 do not contain any grammar explanation at all.

To summarize, there are two books that probably succeeded in terms of simplicity and clarity, although I lack information about the New Headway $4^{\text {th }}$ edition. One book is overly simple and, as a result, may lack clarity. One book is accurate but not simple, one book uses students' native language and two books do not work on grammar.

Figure 20: Breaking the English Barrier introduces language in Spanish

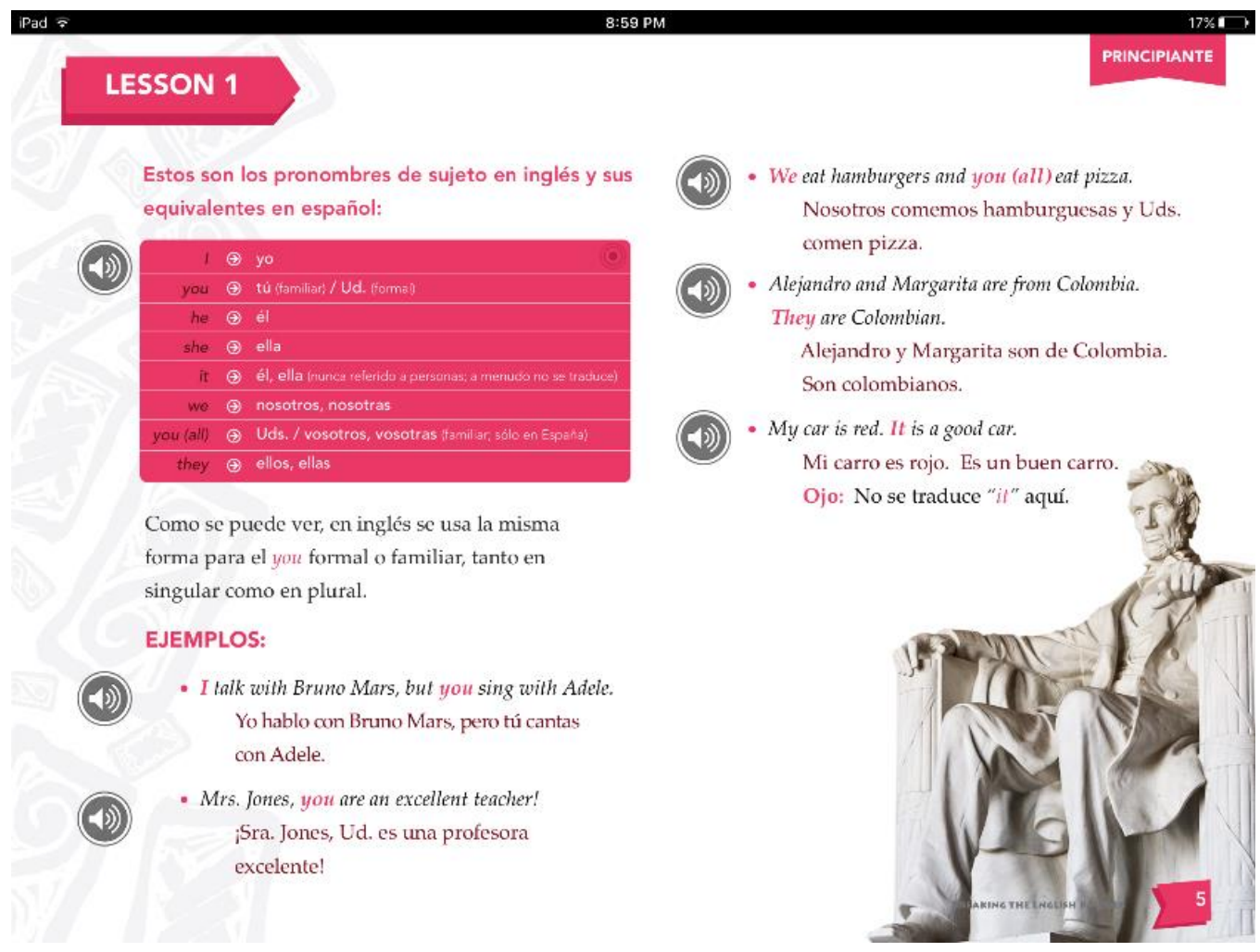

Source: screenshot of Breaking the English Barrier p. 5.

\subsubsection{Focus on form vs. focus on meaning}

In this section of the analysis of grammar, I will investigate whether the selected books give more importance to form or meaning. The first aspect concerns the grammatical structures and rules for combining words while the second aspect has to 
do with the significance of these rules and the situation in which language is used. Based on the views of Ur (1991) and Swan (2006), ideally, a grammar presentation should focus on meaning and written form as well as oral form.

In unit 6 of The New Headway 4th edition, one of the grammar topics is comparatives and superlatives. It is linked to a previous activity in which three cities are compared. Contextualization facilities the understanding of meaning; however, within the unit, there is no explanation about the use of the language presented. The unit has a chart that students should complete with the correct form of each adjective. It also works on oral form as there are two pronunciation exercises in which students listen to and repeat some sentences. The exercises are mostly structure focused: repetitions, fill the gaps and sentence completion. Only at the end of the section are students encouraged to give their opinion and produce language in a more meaningful and independent way (see figure 21).

Figure 21 - The New Headway 4th edition grammar presentation and practice

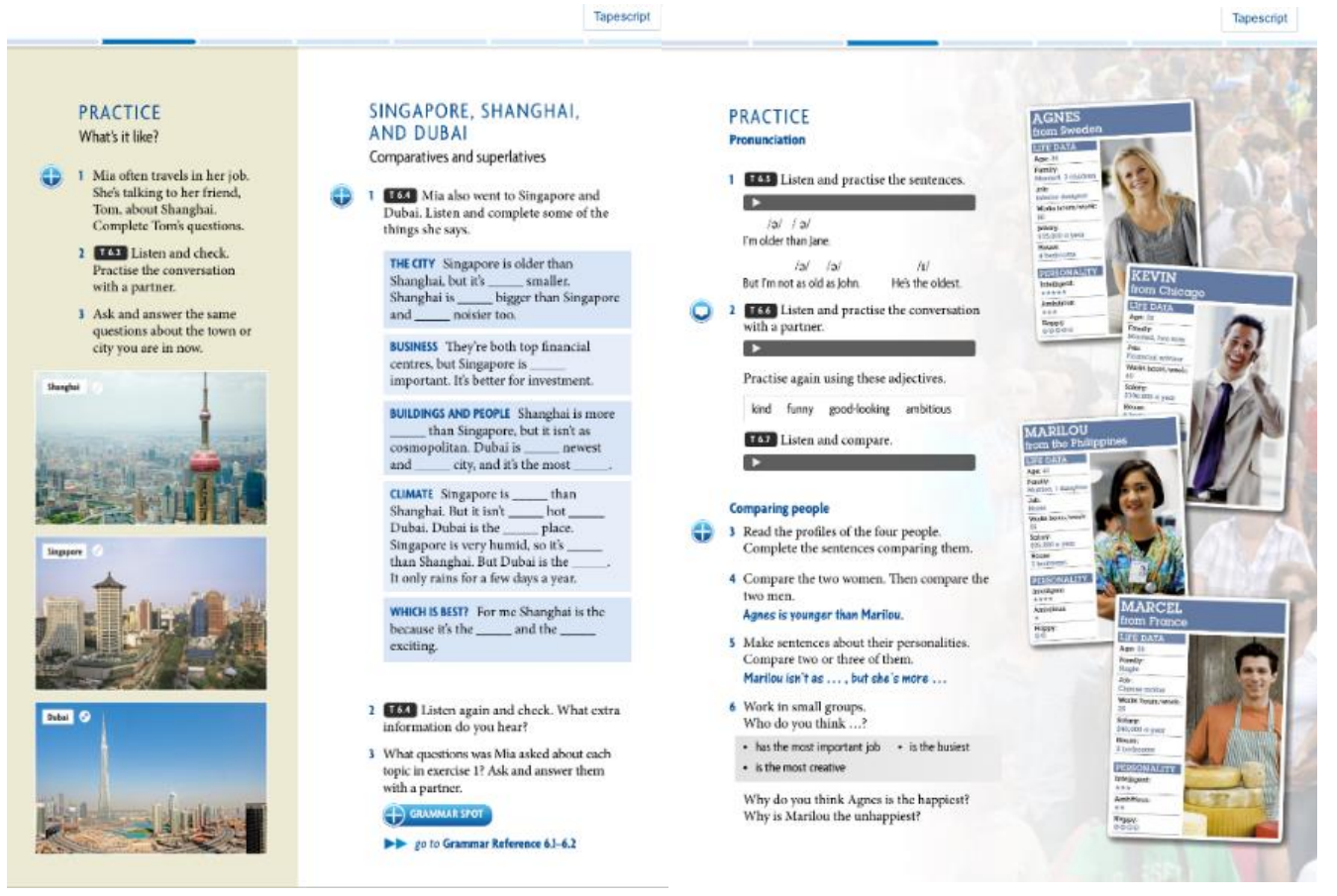

Source: screenshot of pages 39 and 40. 
Study"it" 3 has a similar approach to the New Headway $4^{\text {th }}$ edition, though perhaps it brings a little more balance between form and meaning. At the same time that there is attention to structure, for instance, a list of verbs in the past participle, it also provides students with more opportunities to talk about themselves using the structure they learnt. These are the only two books which have exercises that are meaning focused. Breaking the barrier and UptoDate 5 not only strongly concentrate on explaining the structure rather than use but also have exercises that are limited to filling the gaps, completing sentences and finding the errors (see figure 22). Learn English 4 does not present any grammar practice.

Figure 22: structure focuses exercises
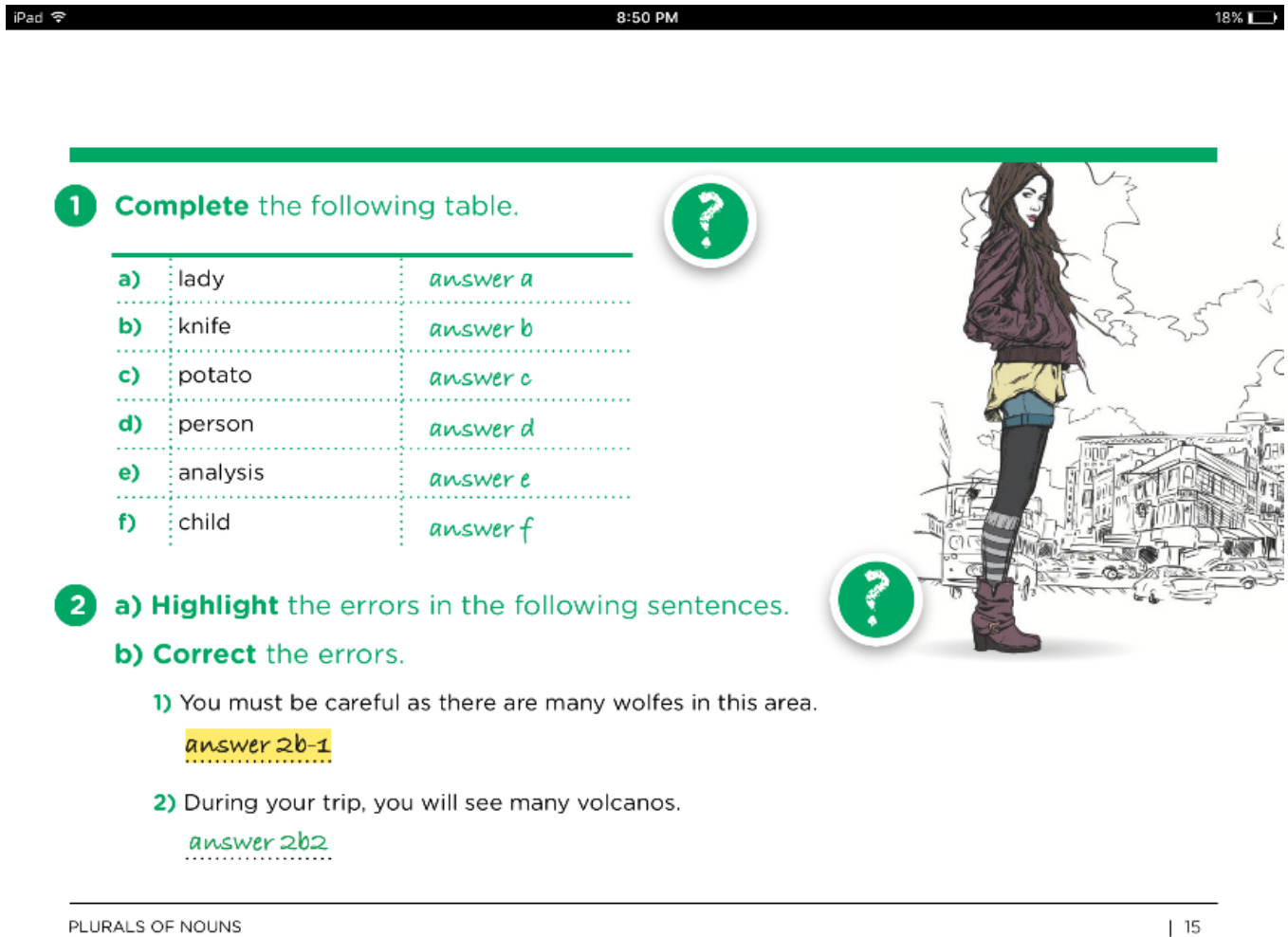

Source: screenshot of UptoDate 5 p. 15.

Neither iLook,iThink, iSpeak nor In class English Speaking Course Book 1 have a grammar section. The second book has a lexical approach to language, though it does not give any explanation about it. I was not able to identify the objective of the lesson, as the collocations do not seen to be part of the same situational context. Still, 
the exercises test meaning. For example, students have to select the correct response for each sentence given (see figure 23). Further on, they are asked to produce their own dialogue. The unit does not test structure at any time.

In short, most of the books have a stronger focus on form. Five are concerned with explaining sentence structure or word formation, and three of them present exercises exclusively on structure. One book seems to have an appropriate balance between meaning, written form and oral form, one does not have a concern with grammar at all, and one shows a concern with meaning despite its lack of context and instructions.

Figure 23 - In class English Speaking Course Book 1 exercises

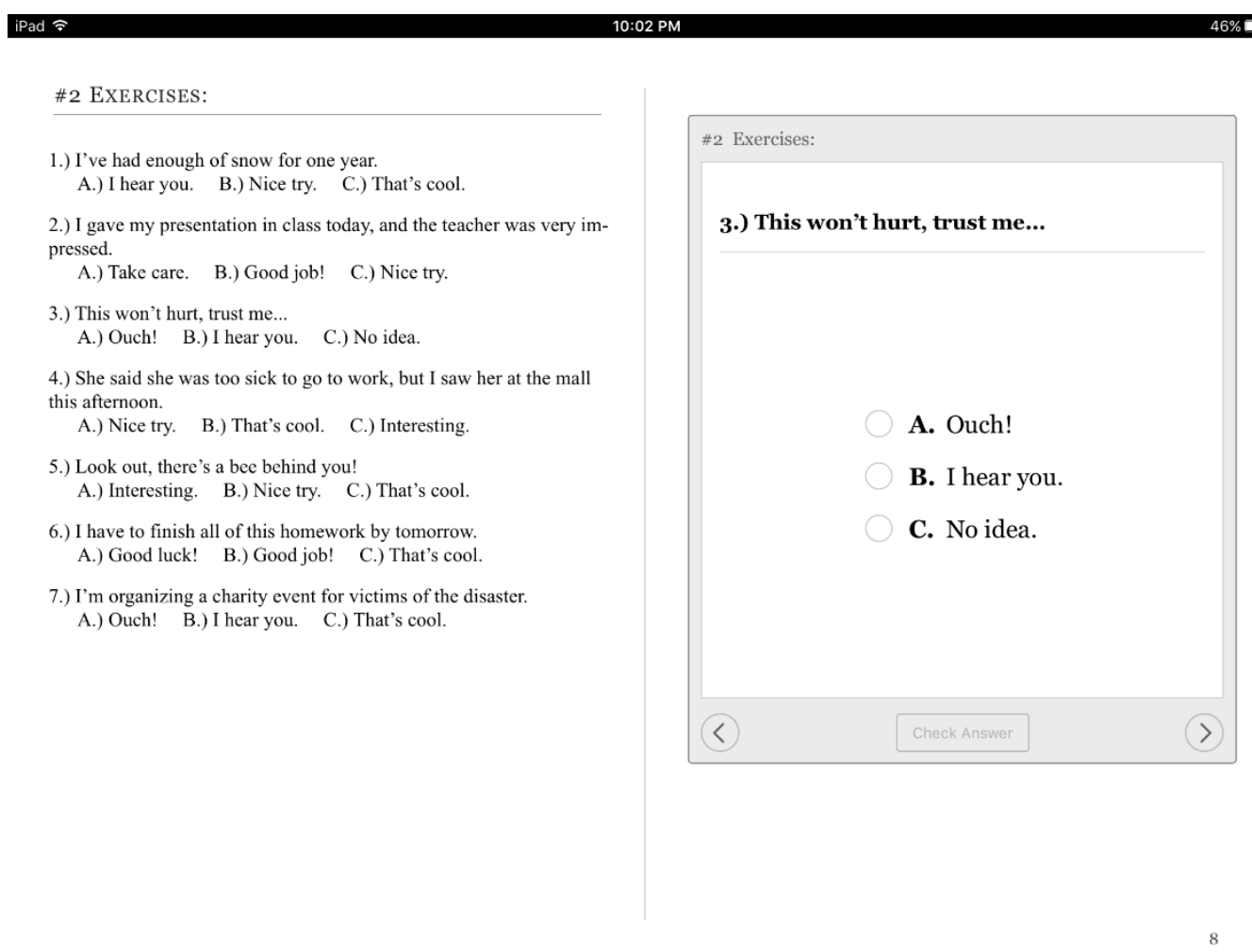

Source: In class English Speaking Course Book 1, p.8.

\subsubsection{Use of digital resources}

Digital features are present in all the books though to different extents. Some use videos, audios and hyperlinks in every page while others simply take advantage 
of the touch screen. This is different from what I analyzed in the section on multimodality, where I checked how visual features might have influenced learning. In this section of the approach to grammar, I will investigate what the use of digital technologies can add to grammar presentations and practices and whether they bring novelty or not.

The New Headway $4^{\text {th }}$ edition and Breaking the Barrier use audios to introduce oral form. The innovation here is that the audio is already in the book, and students can learn pronunciation without the help of a CD player or the teacher, who often speaks the sentence for students to repeat. The result is that learning can become more independent. Another interesting feature that is presented in most books is that all the exercises can be expanded or minimized (see figure 24). That means the books do not have to fit all the information in one page, and this might give an opportunity for a larger number of exercises. However, I would only be able to verify this in a comparative study with printed books.

Figure 24: three expandable exercises on the same page

iPad :

:01 PM

Learn it! The Present Perfect Tense

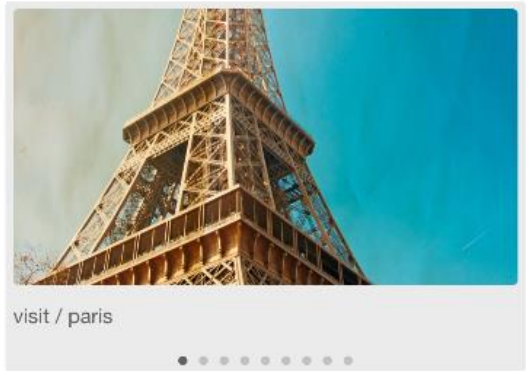

$\square$ My Bucket List

Bucket lists are a list of everything you want to do in

your life. Some people climb mountains, some travel to

strange and amazing places.

Look at the picture to the left. Answer these questions.

1. Have you ever done it? If so, when? What did you do? If not, why not?

2. Think of five more amazing things to do for your own bucket list. Tell the class.

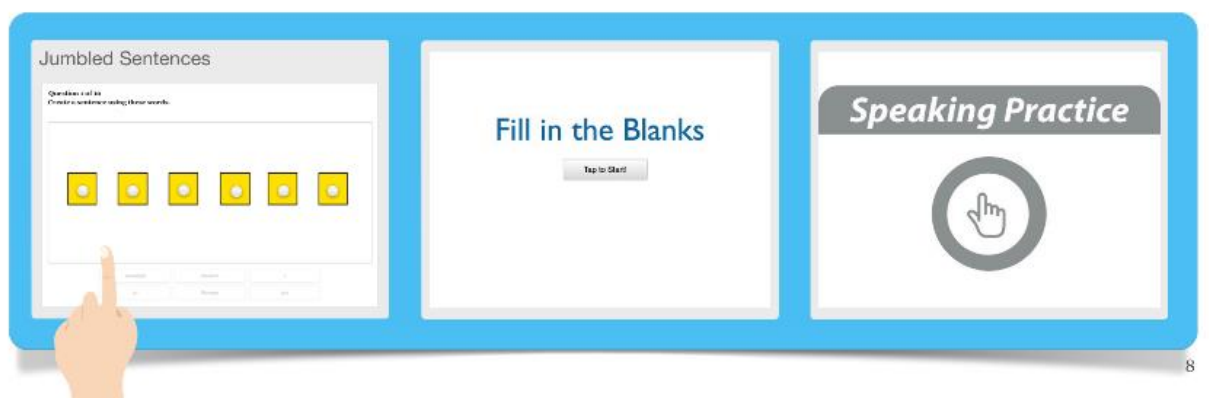

Source: screenshot of Book Study “it” 3, p. 8. 
Both UptoDate 5 and Study "it" 3 take advantage of the device's touchable screen. Instead of using pictures or texts, they use a more dynamic mode to introduce grammar. Students have to tap on the screen for the text and images to appear. These look like short presentations which only move forward when the screen is tapped. The books use this strategy to provide explanation as well as to contextualize language (see figure 25). Study"it" 3 also makes use of a video to model a conversation exercise. Comparable to the audios, it does not rely on another device such as a TV or the teacher to know what to do. Students can watch it by themselves and do the exercise.

Another feature that can make the use of the material more independent is a check answers button. Right after students complete an exercise, they can check it by themselves and do not need the teacher to give them the correct answer (see Figure 26). Five books, all of which contain exercises on grammar, have this button. In class English Speaking Course Book 1 and iLook,iThink,iSpeak do not approach grammar in any way and the book Learn English 4 only uses written text and there are no exercises in it.

Figure 25: Explanations move forwards as students tap the screen

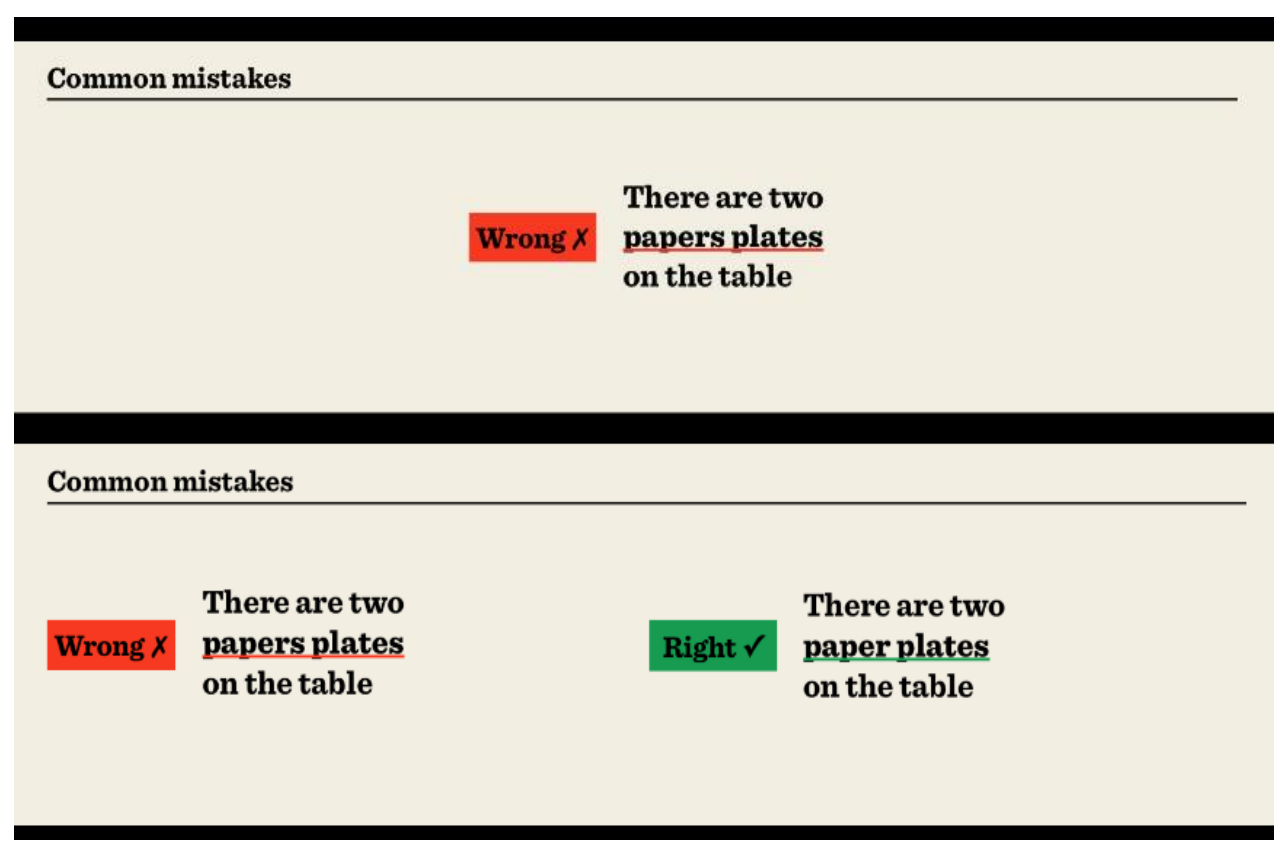

Source: screenshot of UptoDate 5 p. 10. 
Figure 26: The check answer button

iPad $\%$

$14 \% \square$

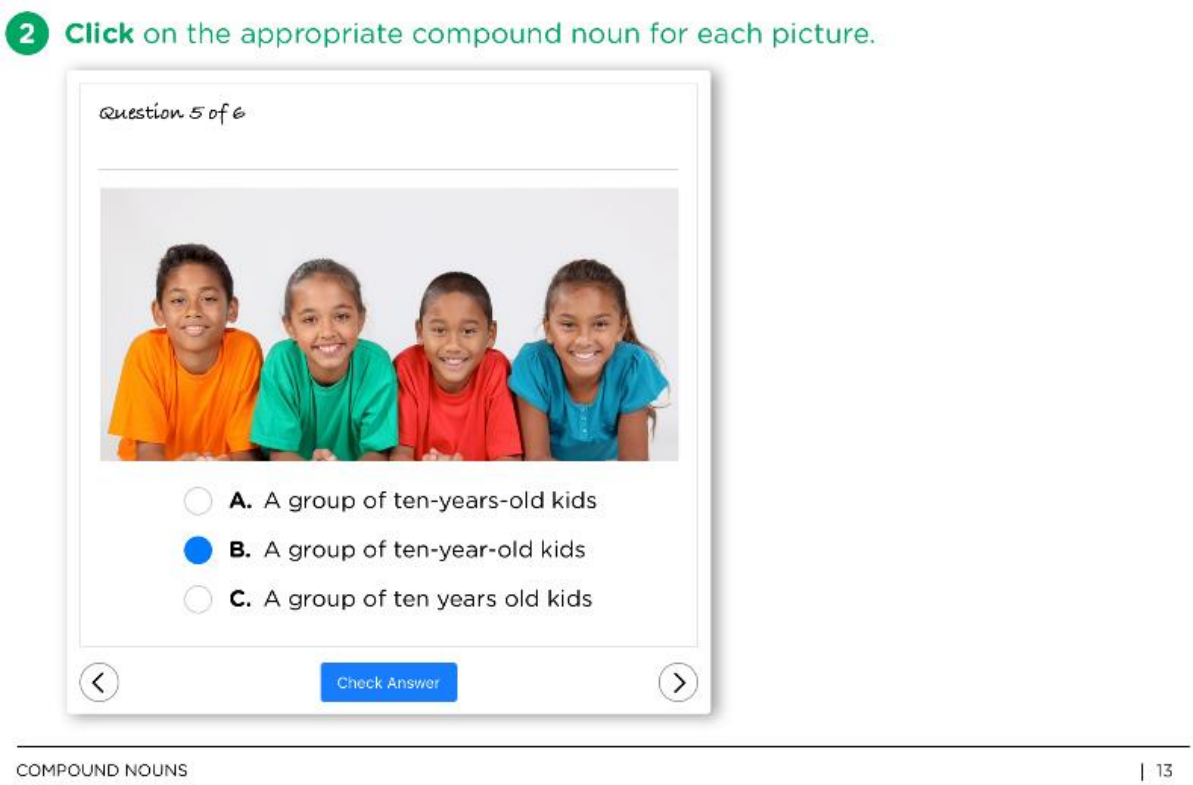

Source: screenshot of UptoDate 5 p. 13.

The use of digital resources is present in EFL digital coursebooks when they deal with grammar. Audio tracks can be useful when presenting oral forms of grammatical structures and the touchscreen makes presentations more dynamic. As well as that, the possibility of minimizing or enlarging exercises allows the possibility of adding more practices to the books and the check button allows students to check answers on their own. Digital resources are useful and might make learning more independent. 


\section{FINAL CONSIDERATIONS}

This monograph addressed the existence of a genre in digital coursebooks for English language teaching. After the analysis of the visual elements and the approach to grammar in seven digital coursebooks, some considerations can be made.

I will begin by talking about multimodality. Modes make contributions to learning. They are socially shaped and therefore collaborate with the creation of meaning. In this monograph, I analyzed images, videos and spatial organization. These semiotic components play diverse roles in the digital books. Images, for instance, show what cannot be described in a text or audio. They can help students form an opinion and possibly engage with the material differently from the way they would engage with printed books. Images and videos can also connect students with the real world by showing authentic pictures or videos, that is, material that was not designed for the coursebook but extracted from other sources.

The visual features in these books can also make learning more autonomous. They can be used to exemplify and model activities. In addition to that, when different semioses are put together, they can allow students to decide how they want to interact with the material. The spatial organization of EFL digital coursebooks can influence how students engage with them as well. By prioritizing one mode over another within a page, the book indicates what is more and less important. Learners will also make epistemic assumptions based on the appearance of the page.

One of my objectives was to try to identify a pattern in terms of content, style and compositional structure, characteristics that, for Bakhtin ([1979] 2010), define a genre. Regarding appearance, the results of the analysis show that every book has its own characteristics that distinguish it from the others, and even within a book the structure might change from page to page or from section to section. Nevertheless, by observing the multimodality chart, I was able to make some generalizations. For instance, the number of pictures in each book shows that most of them are highly visual. In addition, most digital books are designed to be handled in the horizontal position. Videos are not a common feature in EFL digital books, contrary to what could have been expected, considering they are displayed on an electronic device. 
I believe the majority of the books would be recognized as a coursebook for English language teaching just by their appearance. The main reason for that is the similarity of these books with printed, mainstream books of today. Perhaps three of them, Learn English 4, iLook, iThink, iSpeak and In class English Speaking course book 1 would demand a second examination before being classified as a coursebook. The reason for this is their unusual appearance.

Approaches to grammar were another focus of my analysis. What the analysis indicates is that, perhaps not surprisingly, traditional approaches to grammar are more likely to aim at structure rather than meaning and use. They present long explanations of grammar rules, and the exercises ask for sentence completion, which is not typically communicative. Ideally, grammar should be introduced in a clear and simple way, it should be contextualized, and there ought to be a balance between meaning, use and form. Preferably, the grammar presentation also includes visual material. EFL digital coursebooks are recent publications that can take advantage of new technologies to present grammar in more original ways and closer to what would be considered ideal.

The results obtained in my analysis of seven digital coursebooks indicate that these publications do not follow one pattern. Two books do not deal with grammar at all. The lessons in iLook,iThink, iSpeak are based on written texts and they include comprehension exercises and speaking activities. As a whole, it is a book that could be considered innovative for having videos, images and a communicative target. However, my aim was to check innovations in the grammar section, and this book does not contain one. In class English Speaking Course Book 1 delivers "chunks" of language, but they are not contextualized and there is no clarification of meaning, use or form.

One book, Learn English 4, is very traditional. It focuses on structure rather than use, it does not include visual materials, and, in addition, it is oversimplified, which makes the explanation unclear. Two books, Breaking the English barrier and UptoDate 5 , have a more lexical approach with full explanation of grammar items and exercises on structure. The first one does this in Spanish, a peculiar aspect that we can consider positive. On the other hand, there are two books that are less traditional. The New Headway $4^{\text {th }}$ edition is a book that is originally printed and recently has gained a digital version. Its grammar presentation is contextualized and focuses on meaning, use and form. It includes images and exercises, and it moves from focus on structure towards focus on communication. Study it 3 has a similar approach, though it can be said to be 
a little more innovative, as it uses more digital resources like videos in its presentation. However, even in this innovative book, there still remain some conventional aspects such as a list of verbs.

Many of these aspects that are considered as ideal do not rely on digital technology and are not exclusive characteristics of digital coursebooks. Other aspects, such as check button, videos, pages that expand, and so on, are innovations in grammar presentations that can only be found in these new publications. Despite those innovations, my analysis shows that most EFL digital coursebooks still opt for some long-established practices and, in fact, borrow the way EFL printed books approach grammar. As a conclusion, we might say that advances in technology are present and they are useful, although they are not revolutionary. Most digital coursebooks introduce grammar in some way, some of them being more innovative than others.

Most of the books have a good variety of visual elements and some treatment of grammar. So the fact that they all resemble each other indicates they are members of the genre. Genres are relatively stable types of utterance and they may undergo transmutation from time to time. EFL digital books have most probably developed from EFL printed books. Both printed and digital coursebooks are part of an educational culture and have a common aim, which is to teach English as a foreign language. Regarding visuality and language teaching, there are several comparable aspects as well. Regardless of these similarities, they should not be considered the same as printed books, and I will now explain why.

First of all, every new genre is linked to a previous one. These transmutations occur due to changes in social practices. We have seen that the use of new technologies in education has increased, and more schools are adopting digital books. Genres are products of a context of culture and they develop within different fields of communication. EFL digital books have developed within a digital context and are part of a culture that is strongly connected with digital technologies. Both printed and digital books are part of an educational culture, but only digital books are part of this new digital context of culture. Second, the digital books happen in a different medium. The fact they are dependent on an electronic gadget makes them different from printed ones.

However, the connection between these two modes of books deserves further discussion. Digital books only work in an electronic apparatus and are part of a social context that is highly connected to digital technologies. At the same time, they show 
similar characteristics to printed books and they are both part of an educational culture. Taking all these aspects into consideration, I believe the EFL digital coursebook to be a subgenre of the EFL coursebook genre. It was expected that digital publications would take advantage of all the technological options available, to develop their own particular features. In fact, the patterns in this new medium seem to be acquired from the printed book genre. In other words, since the features of the printed version are still very much present in the digital version, maybe that is what is still recognized as typical for the coursebook genre. This is why the digital version can be said to be a subgenre of the printed coursebook.

Besides my interpretations, I recognize that there are limitations to my study. Part of the reason for the limitations is the small quantity of books I had access to. It is possible that a study that used a different gadget or more than one gadget to search for books would have a large sample to analyze. Different criteria could result in different perceptions as well. Another reason for the limitations is that I narrowed my research to a textual and visual analysis of the digital material, and I was not able perceive how students use these coursebooks, nor how much the material could influence how they learn.

Writing this monograph has motivated me considerably, and I would like to continue this research. There are several topics that could be addressed in further studies. I mentioned before that whether the process of publishing a digital book had an influence on some of its characteristics was beyond the scope of my paper. However, as digital books continue to be published, as I expect they will, they might go through reformulations that will change some of their features. Investigating the way students interact with digital material and whether this interaction changes learning is also a possibility. 


\section{REFERENCES}

BAKHTIN, M. Os gêneros do discurso. In: Estética da criação verbal. São Paulo: Martins Fontes, 1997, p. 279-326.

BAZERMAN, C. Genre as social action. In: Gee, j.; Handford, M. The Routledge handbook of discourse analysis. 1. ed. London: Routledge, 2016. p. 226-238.

BEZEMER, J.; Kress, G. Visualizing English: a social semiotic history of a school subject. Visual Communication, v. 8, n. 3. London: SAGE, 2009. p. 247-262.

BHATIA, V.Worlds of written discourse: a genre-based view. London: Continuum. 2004

DIRK, K. Navigating Genres. In: Lowe, C; ZEMLIANSKY, P. Writing spaces: reading on writing, Vol 1. Parlor Press. 2010. p.249-262. Available at: http://writingspaces.org/essays

HEMAIS, B. Práticas pedagógicas no ensino de inglês: Integrando gêneros discursivos e multimodalidade. In: HEMAIS, B.J.C. (Org.). Gêneros discursivos e multimodalidade: Desafios, reflexões e propostas no ensino de inglês. 1. ed. Campinas: Pontes, 2015. p.19-34.

JEWITT, C. Technology, literacy and learning. London: Routledge, 2006.

Jornal da Globo. Mercado de e-books cresce no Brasil com uso cada vez maior nas escolas. Available in: shttp://g1.globo.com/jornal-daglobo/noticia/2015/02/mercado-de-e-books-cresce-no-brasil.html>. Accessed in: 19 fev. 2016.

MARCUSCHI, L. Gêneros textuais emergentes no contexto da tecnologia digital. In: MARCUSCHI, L. A.; XAVIER, A. C. (Org.). Hipertexto e gêneros digitais - novas formas da construção de sentido.3. ed. São Paulo: Cortez, 2015. p.15-80. 
MILLER, C. Genre as Social Action (1984), Revisited 30 Years Later (2014). Letras \& Letras, Vol. 31, 2015. p. 56-72.

MAUGHAN, S. School and library spotlight: How schools buy and use E-Books. Publishers Weekly, 2015. Available in:

shttp://www.publishersweekly.com/pw/by-topic/industry-news/libraries/article/67927school-and-library-spotlight-how-schools-buy-and-use-e-books.html>. Accessed in: 19 fev. 2016.

ROSE, Gillian. Visual methodologies: An introduction to the interpretation of visual materials. London: SAGE, 2007.

SILVA, R. C. O livro didático de inglês como um gênero discursivo multimodal promotor de letramentos múltiplos. In: HEMAIS, B.J.C. (Org.). Gêneros discursivos e multimodalidade: Desafios, reflexões e propostas no ensino de inglês. 1. ed. Campinas: Pontes, 2015. p. 35 - 41.

SOARES, M. O papel do autor de livro didático para o ensino de língua inglesa como uma língua estrangeira: um estudo de identidade autoral. Mestrado-[s.l.] PUC- Rio, 2007.PUC- Rio, 2007.

SOUZA, D. M. Autoridade, autoria e o livro didático. In: CORACINI, Maria José, (Org.). Interpretação, autoria e legitimação do livro didático. Campinas: Pontes, 1999. P. 55-60.

SWAN, M. Teaching grammar - does teaching grammar work? Modern English Teacher, Vol 15, n.2, 2006. Available in: http://www.mikeswan.co.uk/elt-appliedlinguistics/teaching-grammar.htm Accessed in: 14 June, 2016.

TOMLINSON, B. Developing materials for language teaching. London: Continuum, 2003.

UR, P. A course in language teaching. Cambridge [England]: Cambridge University 
Press, 1996.

VILAÇA, M. L. C. Tecnologias e livros didáticos de línguas: novas possibilidades, novos desafios. Cadernos do CNLF, Vol. XVI, № 04, t. 1 - Anais do XVI CNLF, pág. 51-60, 2012. Available at: <http://www.filologia.org.br/xvi cnlf/tomo 1/105.pdf> Accessed in: 14 June, 2016.

A elaboração de materiais didáticos de línguas estrangeiras: autoria, princípios e abordagens Cadernos do CNLF, Vol. XVI, № 04, t. 1 - Anais do XVI CNLF, pág. 1202-1210, 2012. Available at: $<$ http://www.filologia.org.br/xvi cnlf/tomo 1/004.pdf> Accessed in: 14 June, 2016. 